\title{
Failure Characteristics of Joint Bolts in Shield Tunnels Subjected to Impact Loads from a Derailed Train
}

\author{
Qixiang Yan, Zhixin Deng, Yanyang Zhang, and Wenbo Yang \\ Key Laboratory of Transportation Tunnel Engineering, Ministry of Education, Southwest Jiaotong University, Chengdu, Sichuan, China \\ Correspondence should be addressed to Yanyang Zhang; yanyang.zhang@swjtu.edu.cn
}

Received 28 October 2016; Revised 5 January 2017; Accepted 10 January 2017; Published 13 February 2017

Academic Editor: Tony Murmu

Copyright (C) 2017 Qixiang Yan et al. This is an open access article distributed under the Creative Commons Attribution License, which permits unrestricted use, distribution, and reproduction in any medium, provided the original work is properly cited.

\begin{abstract}
Impact loads generated by derailed trains can be extremely high, especially in the case of heavy trains running at high speeds, which usually cause significant safety issues to the rail infrastructures. In shield tunnels, such impact loads may not only cause the damage and deformation of concrete segments, but also lead to the failure of segmental joint bolts. This paper presents a numerical study on the failure behavior of segmental joint bolts in the shield tunnel under impact loading resulting from train derailments. A threedimensional (3D) numerical model of a shield tunnel based on the finite element (FE) modelling strategy was established, in which the structural behavior of the segmental joint surfaces and the mechanical behavior of the segmental joint bolts were determined. The numerical results show that the occurrence of bolt failure starts at the joints near the impacted segment and develops along the travel direction of train. An extensive parametric study was subsequently performed and the influences of the bolt failure on the dynamic response of the segment were investigated. In particular, the proposed FE model and the analytical results will be used for optimizing the design method of the shield tunnel in preventing the failure of the joint bolts due to the impact load from a derailed HST.
\end{abstract}

\section{Introduction}

Nowadays, the boom in the popularity of the high-speed train (HST) industry has brought about great convenience to public transportation; however, this has generated great safety issues. The research results in $[1,2]$ showed that train derailment is one of the most critical safety issues. In recent years, a large number of train derailments were reported around the world, some of which happened in shield tunnels. In February 2011, a HST derailment took place in a railway tunnel in Korea at speed of more than $300 \mathrm{~km} / \mathrm{h}$. More recently, in September 2016, a HST derailment happened in a railway tunnel in the UK. These accidents not only caused casualties and property damage, but also posed a huge threat to the structural safety of the railway tunnels. From the structural point of view, a derailed HST may provide significant impact load directly to the concrete segments in the shield tunnel. This impact load may not only result in damage to the concrete segments, but also cause the failure of bolts between adjacent segments. As a result, bolt failure, segment dislocations and deformations, and tunnel lining instability may occur, which may eventually destroy the structural stability of the shield tunnel. Thus, the bolt failure behavior plays an essential role in studying the structural behavior and assessing the safety of the shield tunnels.

At present, high-speed railway systems are critical components in the public transportation network, not only in China but also all over the world. Over the past few decades, there has been a growing interest in studying the HST impact response and assessing the HST safety. A large amount of experimental and numerical work [3-8] was carried out to assess the crashworthiness performance and energy absorption behavior of rail vehicles. Research [9-14] was also carried out on investigating the interaction between rail vehicles and rail infrastructures, which are mainly focused on the structural behavior of rail tracks and railway bridges. More recently, Yan and his coresearchers [15] carried out numerical and analytical studies on the dynamic behavior of a doublelined shield tunnel subjected to HST impact loads. In [15], time history curves of the HST impact load were provided in terms of different train configurations, speeds, and impact angles. Moreover, it was found that, instead of establishing 
a complex vehicle model, applying the impact load directly to the tunnel structure was more computationally effective in the numerical study on the dynamic response of the tunnel structure under the HST impact load [15]. However, Yan et al's work was mainly focused on the influences of HST impact loads on tunnel segments without considering the failure characteristics of joint bolts, which were used to connect adjacent segments. Besides, it was found by the authors that there was a research gap on the failure characteristics (e.g., failure time, types, and sequence) of joint bolts and their influence on the dynamic response of segmental lining subjected to HST impact loads. As most of the previous researchers focused on the safety and optimization design of the rail vehicles or rail tracks, the structural performance of the shield tunnels under HST train impact loads should be assessed. Moreover, the research on the failure characteristics of the joint bolts and their influences on the structural behavior of the shield tunnels should take priority.

Major research efforts on the structural behavior of the segmental joints had been devoted to the numerical work. In [16-18], a reduction factor was approximately applied to the flexural rigidity of tunnel lining structures to take into account the effect of the segmental joints. This method had the advantage of simple calculation; however, it failed to reflect the complex structural behavior of the joints and especially ignored the openings and dislocations of the joints. Later, as an improvement, FE models using shell (or beam) elements with joint springs were employed to achieve a better understanding of the structural behavior of segmental joint under different loading conditions [19-22]. In these models, the segments were modelled using beam or shell elements, while a set of springs were applied to simulate the segmental joints. However, there was an intrinsic difficulty in determining the equivalent spring rigidity through experimental tests and in investigating the interactions between the circumferential joint surfaces of two adjacent segments. With the development of modelling techniques, researchers [2325] paid more attention to advanced three-dimensional (3D) FE models, in which the joints were modelled using detailed modelling techniques. Although full 3D models of bolts and segments could provide accurate results, they require very complex considerations for the contact relationships between the numerous bolts and segments. This will lead to lower computational efficiencies and result in convergence problems during numerical analyses. In addition, the detailed modelling techniques are still not able to directly provide full expressions of the dynamic changes of internal forces of the joint bolts.

It has been known that joint bolt is one of the most important components in the segmental joint, and finite element (FE) method is the one of the most popular numerical modelling approaches employed in the research on shield tunnels. Therefore, it is important to choose an appropriate numerical model for the segmental joint to provide a better understanding of the failure characteristics of the joint bolts under the HST impact load. In this paper, a numerical investigation of the shield tunnel subjected to a specific impact load due to the HST derailment is presented with the main aims of (1) revealing the failure characteristics of the joint

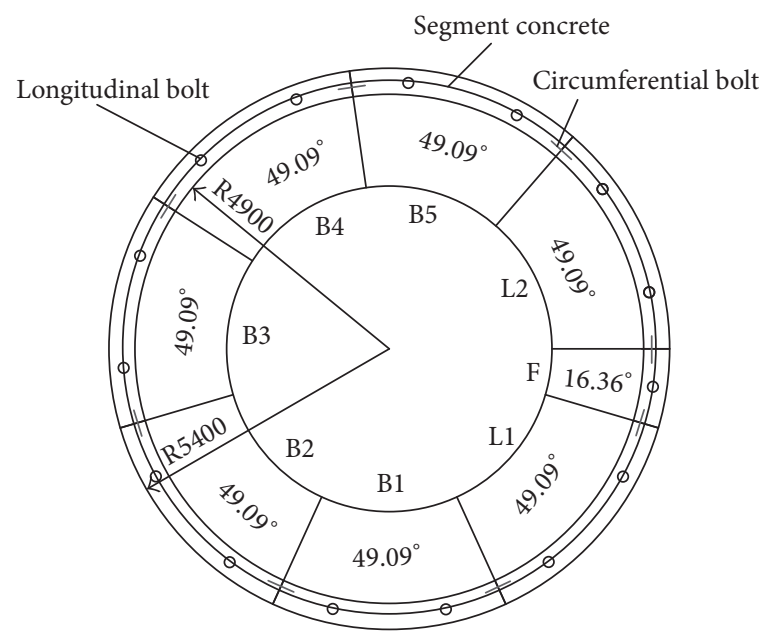

FIGURE 1: The cross section of the investigated tunnel lining.

bolts and (2) examining the influence of bolt failure on the structural behavior of the shield tunnel. In the following, an advanced 3D FE model was proposed to accurately reproduce the procedure of HST impact load on the shield tunnel. Particularly, the joint bolts are simulated by using connector elements in ABAQUS [26], which not only characterized the tension, shear, flexural stiffness, and the failure state of the bolt, but also substantially saved the computational resources. Subsequently, based on the proposed 3D model, the bolt failure behavior is carefully examined and discussed. Meanwhile, a comprehensive parametric study is performed to investigate the influences of bolt failure on the dynamic response of the segment in terms of the damage evolution and displacement conditions. Finally, a comparative analysis considering three different impact loading conditions is performed to reveal the influence of different train running speeds on the failure characteristics of the joint bolt.

\section{Numerical Model}

A numerical model of the shield tunnel is proposed here to offer a clear understanding of the dynamic response of the tunnel lining. In particular, the failure behavior of joint bolts in the tunnel subjected to the impact loading from the HST derailment was carefully examined. Numerical simulations were performed using a general FE package, ABAQUS 6.10 [26], in which both the material and the geometric nonlinearities were considered. Detailed descriptions of the FE model are given as follows.

2.1. General Description. The numerical example considered here is based on a typical shield tunnel that can be found in high-speed railway systems in China. Figure 1 presents the cross section of the analyzed tunnel. The outer and inner diameters of the tunnel are $10.80 \mathrm{~m}$ and $9.80 \mathrm{~m}$, respectively. The segment thickness and width are $0.50 \mathrm{~m}$ and $2.00 \mathrm{~m}$, respectively. And the surrounding rock is considered as $80 \mathrm{~m}$ long, $40 \mathrm{~m}$ wide, and $80 \mathrm{~m}$ high. The material properties of the lining and the surrounding rock are provided in Table 1, 
TABLE 1: Material parameters.

\begin{tabular}{lccccc}
\hline Material & Density, $\rho\left(\mathrm{kg} / \mathrm{m}^{3}\right)$ & Young's modulus, $E(\mathrm{GPa})$ & Poisson's ratio, $v$ & Angle of friction, $\varphi\left(^{\circ}\right)$ & Cohesion, $c(\mathrm{MPa})$ \\
\hline Siltstone & 2460.0 & 19.50 & 0.205 & 38.0 & 3.75 \\
Sandstone & 2580.0 & 25.0 & 0.159 & 42.0 & 2.50 \\
Segment lining & 2400.0 & 34.5 & 0.200 & - & - \\
\hline
\end{tabular}

TABLE 2: Material properties for joint bolts.

\begin{tabular}{lcccccc}
\hline Parameter & Class & Size $(\mathrm{mm})$ & Density $\left(\mathrm{kg} / \mathrm{m}^{3}\right)$ & Young's modulus $(\mathrm{GPa})$ & Poisson's ratio & Effective sectional area $\left(\mathrm{mm}{ }^{2}\right)$ \\
\hline Value & 8.8 & 36 & 7800 & 206 & 0.3 & 816 \\
\hline
\end{tabular}

while the mechanical properties of the joint bolts are listed in Table 2.

Eight-node 3D hexahedral elements with reduced integration (C3D8R) are used to discretize the wall rock and the tunnel segments. A typical FE mesh employed in the current study is shown in Figure 2. An elastoplastic constitutive relationship based on the Mohr-Coulomb criterion is employed to represent the soil material for surrounding rock of the tunnel. Regarding the reinforced concrete material in the segments, an elastoplastic constitutive model is employed, while the stress-strain relationship is obtained from [27]. Besides, infinite element is used to simulate the absorbing boundary in the infinite or semi-infinite domains. As the presence of excessive joint interfaces and joint bolts could eventually increase the computational cost, the influences of bolt holes and rubber blankets between the joints are not considered in this study. Besides, only the segmental ring under the HST impact load and its two adjacent rings (in total three rings) are simulated as assembled FE blocks connected using the joint bolts.

The detailed description of the three lining rings is shown in Figure 3, in which the driving direction of the HST and the three segments (F1-F3) subjected to the HST impact load are also provided. On the other hand, the segmental joints in other segmental rings in the shield tunnel are simulated based on simplification via reducing the elastic modulus of the concrete joints based on the equivalent flexural rigidity according to [28]. In order to clearly investigate the structural behavior of the shield tunnel under the HST impact load, monitoring points are applied in the proposed FE model. The detailed arrangements of the monitoring points are shown in Figure 4. In total, there are fifteen monitoring points (number 1 to number 15) with a $0.5 \mathrm{~m}$ distance between each other on the intrados of the tunnel lining, in which point number 8 is at the center of the three segments under the impact load in the longitudinal direction.

2.2. Modelling Approaches for Segmental Joints. In the shield tunnel, the lining system is mainly made up of concrete segments and joint bolts. Due to the contribution of the bolt connection, relative motions and constrained relationships between two adjacent segments are usually found. Thus, the connection (defined as the segmental joint) between two adjacent segments usually shows complex mechanical behavior and has relatively lower carrying capacity compared with the concrete segment. From the structural point of view, a segmental joint is mainly composed of two components, which are the joint surfaces and the joint bolts, as shown in Figure 5. In practical lining structure, the tensile resistance of the segmental joint is determined by the joint bolt, while the shear and flexural resistances are mainly determined by the joint surface. However, when the tangent force on the joint surface is larger than the friction on the concrete, the bolt will carry part of the tangent force. In addition, the flexural performance of the joint is determined by both of the joint surface and the joint bolt, where the bolt mainly provides contribution by changing the location of the neutral axis (see Figure 5).

Based on the above discussions, 2-node connector elements were used to simulate the physical connections (joint bolts) and constrained relationships in the segmental joints in the proposed FE model. The employed connector element consisted of two nodes, which were coupled with corresponding segments, respectively. The position and motion of the second node were measured relative to the first node. The stiffness of the connector element was defined based on the mechanical properties of the bolt. By using the connector element, the corresponding force or moment can be obtained when there are relative motions between the two nodes of the connector element. According to the intrinsic characteristics of the segmental joint, the "bushing" connector type was assumed between the two nodes of the connector element, where the relative translations and rotations between the connecting points could be realized in any direction. As illustrated in Figure 6, the "bushing" type connector element had 12 nodal degrees of freedom, which were used to define six relative motion components (three translations, $u 1, u 2$, and $u 3$, and three rotations, $u r 1$, $u r 2$, and $u r 3$, in local Cartesian directions). Accordingly, the tensile force and shear force were obtained when the relative translations between the two nodes of the connector element were generated along the directions of segment opening and dislocation, respectively. In addition, the moment can be obtained when there were relative rotations between the two nodes of connector element in rotation directions.

"Node-to-surface coupling" between the nodes at the two ends of connector element and the corresponding joint surfaces of segment were employed to transmit the resultant force and moment between the bolt and the segment, as shown in Figure 7. The proposed FE model for the joint bolt was able to capture the major mechanical behavior of the bolt in terms of tension, shear, and bending and realize 


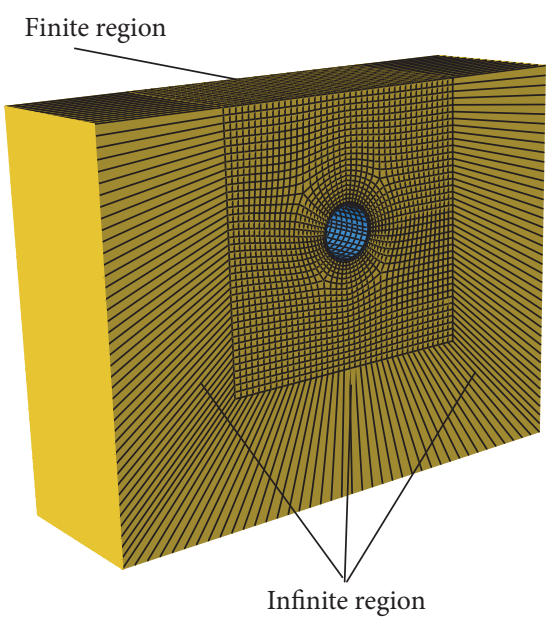

(a)

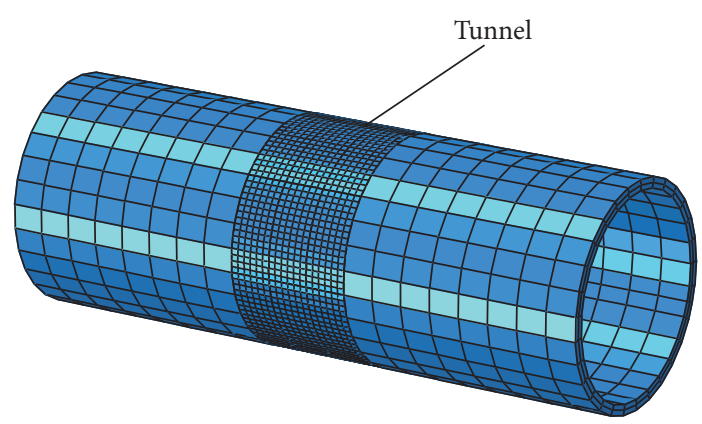

(b)

FIgURE 2: Employed finite element model: (a) the wall rock in the stratum; (b) the investigated tunnel lining.

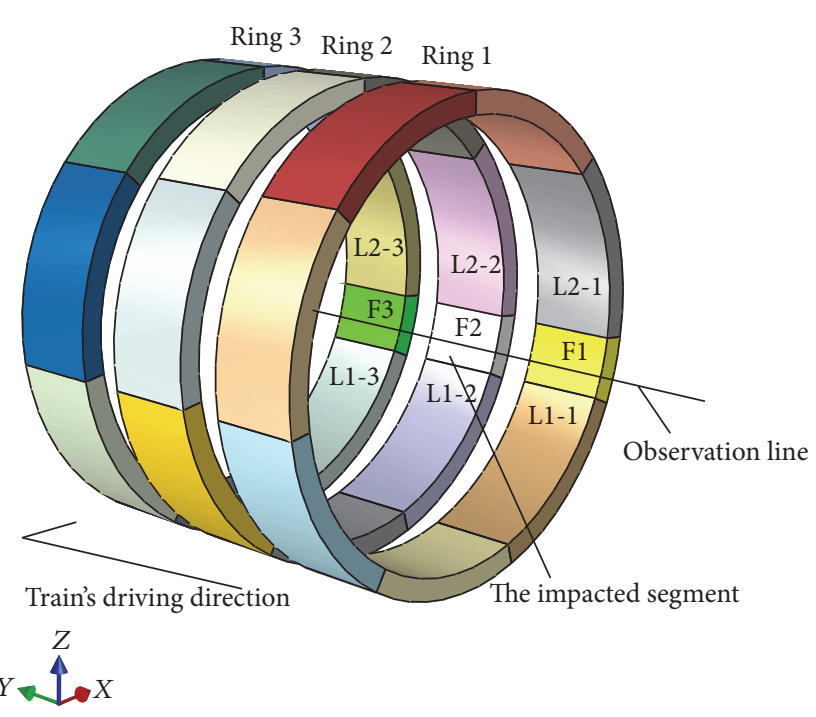

FIgURE 3: Schematic diagram of the segmental lining.

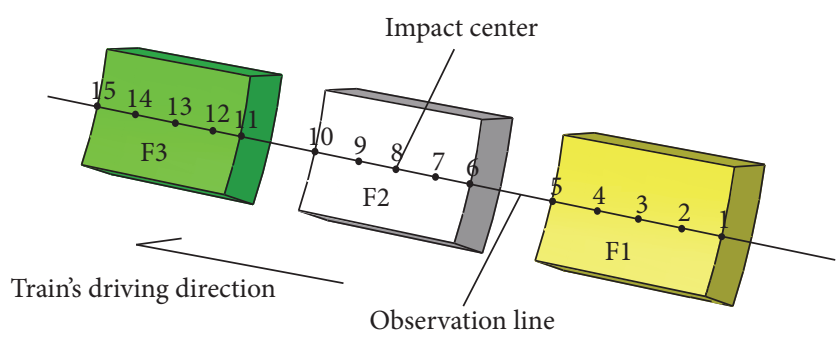

FIGURE 4: Arrangement of the monitoring points.

the relative translation and rotation between the two bolt ends in any direction. Regarding the interaction between the adjacent segments, interface elements with "hard contact" were employed to transmit the contact pressure between the joint surfaces of the adjacent segments. Moreover, the penalty

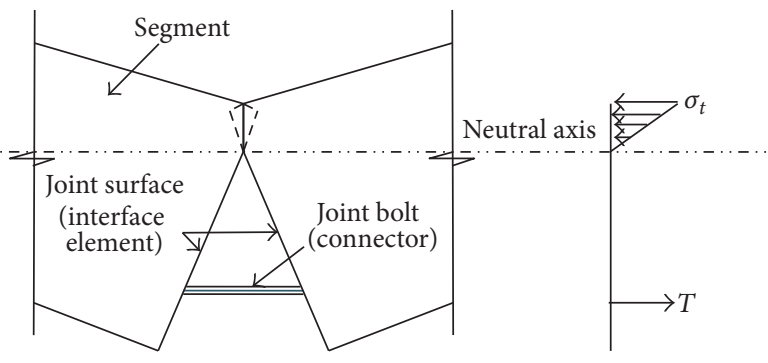

FIGURE 5: Mechanical behavior and theoretical model of the segmental joint.

function method was used to take into account the tangent contact behavior of the interface element and to reflect the relative friction between the joint surfaces of the adjacent segments with the friction coefficient $\mu=0.6$ [15].

2.3. Damage Evolution Model for Joint Bolts. In order to better investigate the failure characteristics of the joint bolt during the HST impact loading process, it was necessary to choose an appropriate damage evolution model for the bolt. In general, the failure behavior of the bolt is usually divided into two modes: (a) failure with progressive damage and (b) failure with instant complete damage, as shown in Figure 8 . When the damage of the bolt is not considered, the force response of the bolt shows linear elastic behavior (see the straight line, $O \rightarrow A$ ). When the failure of the bolt is considered as progressive damage model, the force response is defined as the broken line, $\mathrm{O} \rightarrow I \rightarrow M$ (see Figure 8 ). When the failure of the bolt is considered as instant complete damage, the force response is defined as line $O \rightarrow I \rightarrow D$ (see Figure 8). In the last failure mode (line $O \rightarrow I \rightarrow D$ ), the displacement $U_{I}$ is not increased when the force response reaches point $I$ (the initial damage point). In the meantime, the scalar damage variable $d$ changes from 0 to 1 instantly, and the force $F_{I}$ was reduced to 0 , which indicated that the failure 


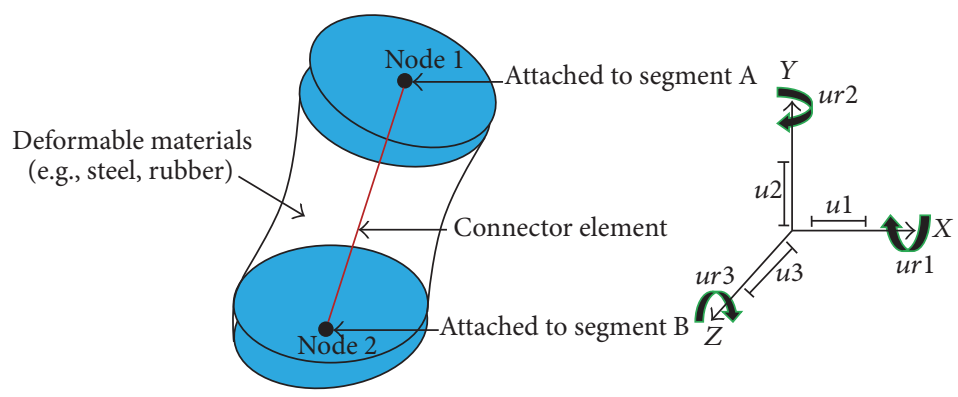

FIGURE 6: Schematic diagram of "bushing" and the relative motion between the two ends of the connector element.

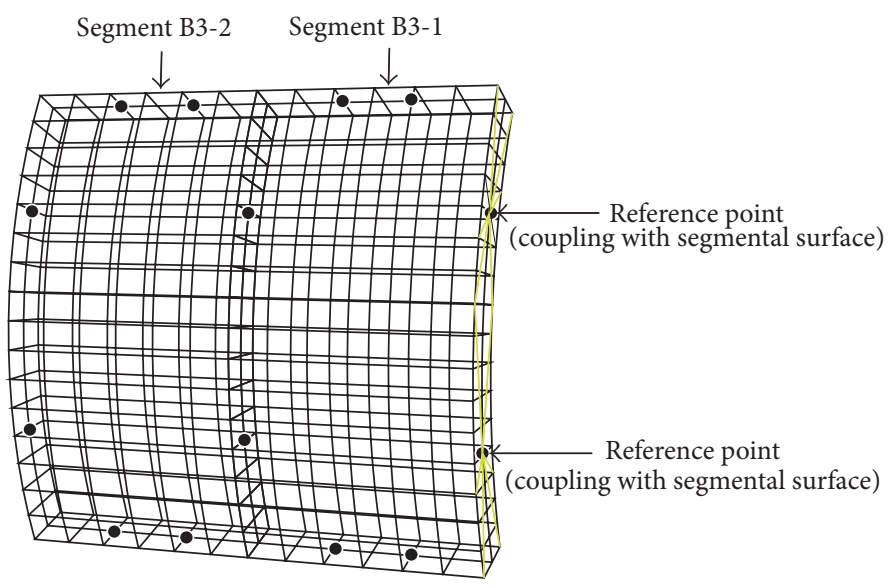

(a)

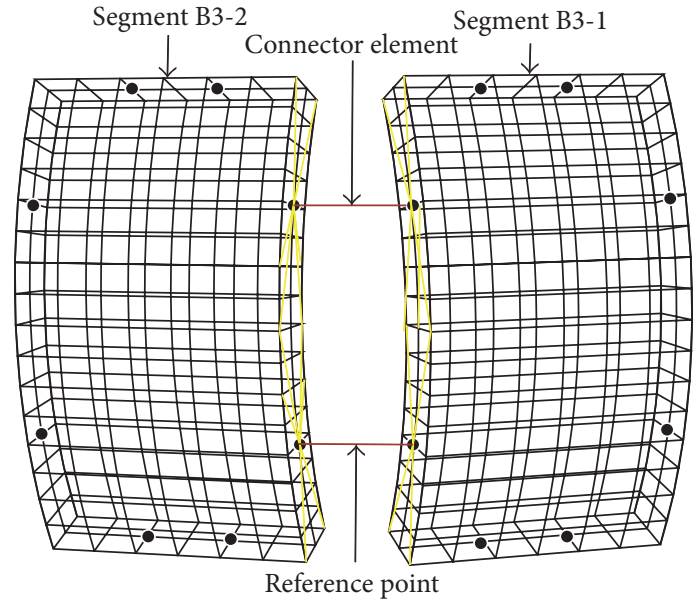

(b)

FIGURE 7: "Node-to-surface coupling" and the arrangement of reference points and connector element (e.g., segments B3-1 and B3-2) (a) without relative movement between adjacent segments and (b) with relative movement between adjacent segments.

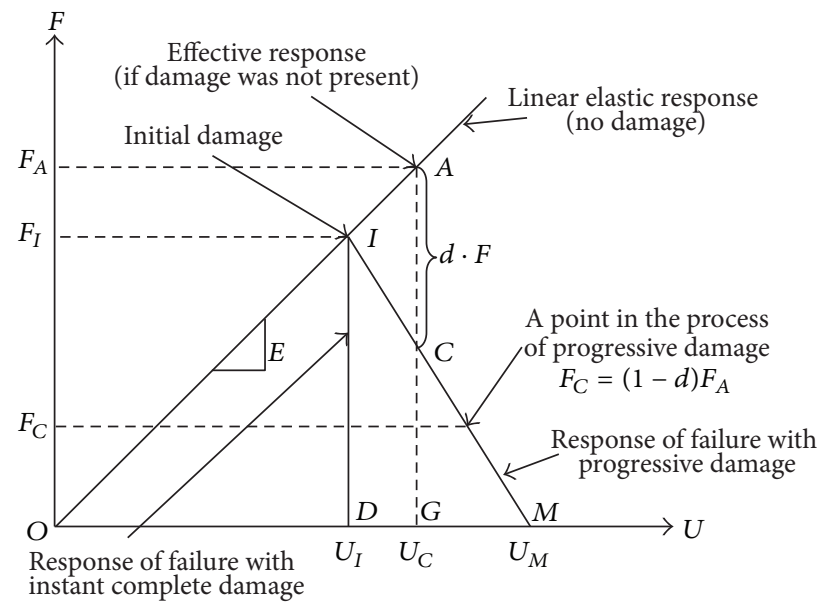

Figure 8: Damage evolution law for the bolt behavior. Note: $U_{I}, U_{C}$, and $U_{M}$ are displacement values of points $I, C$, and $M$, respectively; $F_{I}$, $F_{C}$, and $F_{A}$ are forces of points $I, C$, and $A$, respectively, where $F_{C}=(1-d) F_{A} ; E$ is the elasticity modulus of connector element; $d$ is the scalar damage variable of the connector element.

of the bolt occurs instantly. Due to the instantaneousness and ferocity of the HST impact load, the failure mode of the joint bolt in this study is considered as instant complete damage. Thus, no matter which force (e.g., tensile force and shear force) in the bolt reaches its ultimate bearing capacity, the bolt is regarded as failure instantly, and the failure bolt is subsequently removed from the FE model.

In the current study, although the "bushing" type connector element for the bolt was able to capture the tensile, shear, and flexural stiffness independently, the tensile and shear 


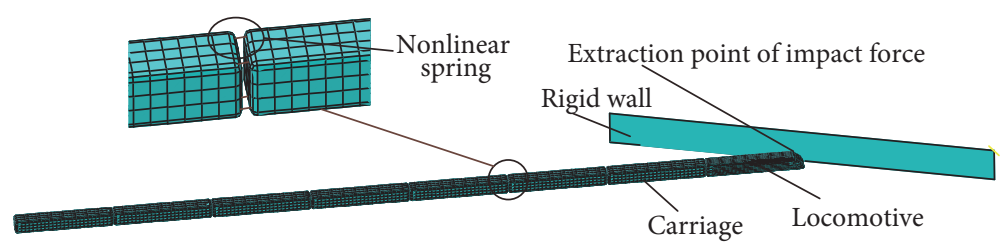

Figure 9: 3D FE model of a typical train configuration [15].

TABLE 3: Mechanical properties for joint bolts.

\begin{tabular}{lc}
\hline Parameter & Value \\
\hline Ultimate tension strength $(\mathrm{MPa})$ & 800.00 \\
Ultimate shear strength $(\mathrm{MPa})$ & 586.40 \\
Ultimate tension force $(\mathrm{kN})$ & 652.80 \\
Ultimate shear force $(\mathrm{kN})$ & 478.50 \\
Tension stiffness $(\mathrm{EA})(\mathrm{MN})$ & 168.10 \\
Shear stiffness $(\mathrm{GA})(\mathrm{MN})$ & 64.65 \\
Flexural stiffness $(\mathrm{EI})\left(\mathrm{kN} \cdot \mathrm{m}^{2}\right)$ & 16.98 \\
\hline
\end{tabular}

failure of the bolt was only considered due to the minimal effect of bending moment on the bolt failure. Besides, the ultimate tensile and shear forces of the bolt were regarded as the product of the ultimate tension and shear strengths and the effective section area of the bolt, respectively. The ultimate tensile strength, $\sigma_{t}$, and the ultimate shear strength, $\tau$, of the bolt in the analyzed tunnel were $800 \mathrm{MPa}$ and 586.4 MPa, respectively [29]. The mechanics properties of the bolt are listed in Table 3. In total, there were 108 joint bolts in the tunnel lining. Accordingly, 108 "bushing" type connector elements were employed in the proposed FE model for the shield tunnel.

2.4. Loading Scheme for the HST Impact Load. As the train model is not actually simulated in the proposed FE model, the impact due to the HST derailment was simulated through applying an oblique impact load on the intrados of the target segment (segment F2). The impact load was obtained as an approximate average surface force based on the impact loading position and the action range based on Yan et al.s study in [15]. In Yan et al.'s study [15], a 3D FE model of a HST against a rigid wall (see Figure 9) was established to obtain the train-to-tunnel impact force. It should be noted that the impact load was obtained by using Yan et al's train model [15] with a running speed of $200 \mathrm{~km} / \mathrm{h}$, which is the minimum running speed for high-speed railways in China. As illustrated in Figure 9, the train model employed in the study was composed of one locomotive and eight carriages. The length, width, height, and coupler center line space of the locomotive were $25.4 \mathrm{~m}, 3.4 \mathrm{~m}, 3.7 \mathrm{~m}$, and $25.7 \mathrm{~m}$, respectively, while the length, width, height, and coupler center line space of the carriages were $24.5 \mathrm{~m}, 3.4 \mathrm{~m}, 3.7 \mathrm{~m}$, and $25 \mathrm{~m}$, respectively. For simplicity, small local chamfers of the train body and small components which were not affected by the impact load were not considered in the train model [15]. Besides, thin-shell elements were used to

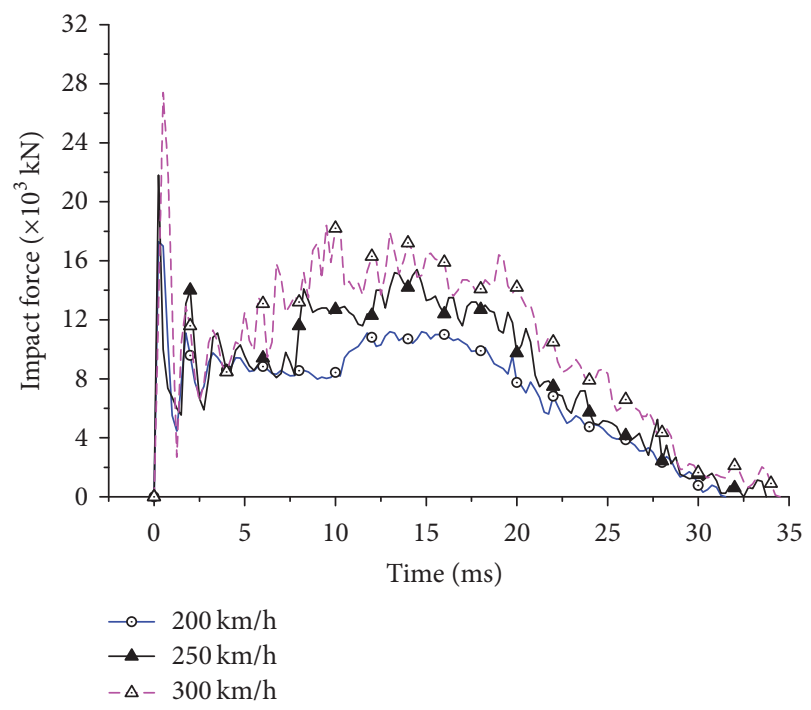

FIGURE 10: Impact force of a train (with running speeds of $200 \mathrm{~km} / \mathrm{h}$, $250 \mathrm{~km} / \mathrm{h}$, and $300 \mathrm{~km} / \mathrm{h}$ and with an impact angle of $12.5^{\circ}$ ) [15].

simulate the outer shape of the train model, which is made of aluminium alloy. Moreover, the approximate equivalent stiffness and mass distribution of the train body were realized by embedding foam-core material and glass-fiber reinforced plastics inside the train body [15]. The material properties for the train body are provided in Table 4 according to the practical material properties used in the HST. Meanwhile, nonlinear springs with stiffness of $2000 \mathrm{kN} / \mathrm{m}$ and damping of $40 \mathrm{kN} / \mathrm{m}$ were adopted to simulate the coupler buffer device between the carriages. In addition, the interaction between the surface of the locomotive and the rigid wall was assumed as plane-plane contact behavior, in which the normal contact was assumed as "hard contact." According to Yan and his coworkers [15], the penalty function method was employed to reflect the tangential contact with the static friction coefficient, 0.1 , and the dynamic friction coefficient is defined as 0.05 .

The impact load curves according to the same train configuration with 8 carriages (as shown in Figure 9) at running speeds of $200 \mathrm{~km} / \mathrm{h}, 250 \mathrm{~km} / \mathrm{h}$, and $300 \mathrm{~km} / \mathrm{h}$ with an oblique impact loading angle of $12.5^{\circ}$ are provided in Figure 10. The target segment (F2) and its adjacent segments in the longitudinal direction (F1 and F3) and in the circumferential direction (L1-2 and L2-2) and other surrounding segments (L1-1, L1-3, L2-1, and L2-3) are illustrated in Figure 11. Dynamic analysis is subsequently performed based on the 
TABLE 4: Material properties for the train model [15].

\begin{tabular}{lcccc}
\hline Material type & Elastic modulus $(\mathrm{MPa})$ & Poisson's ratio & Density $\left(\mathrm{kg} / \mathrm{m}^{3}\right)$ & Yield strength $(\mathrm{MPa})$ \\
\hline Aluminium alloy outer profile & 70000.0 & 0.30 & 2700.0 & 225.0 \\
Foam core & 105.0 & 0.25 & 27.0 & $/$ \\
Glass-fiber reinforced plastics & 8400.0 & 0.40 & 1600.0 & 150.0 \\
\hline
\end{tabular}

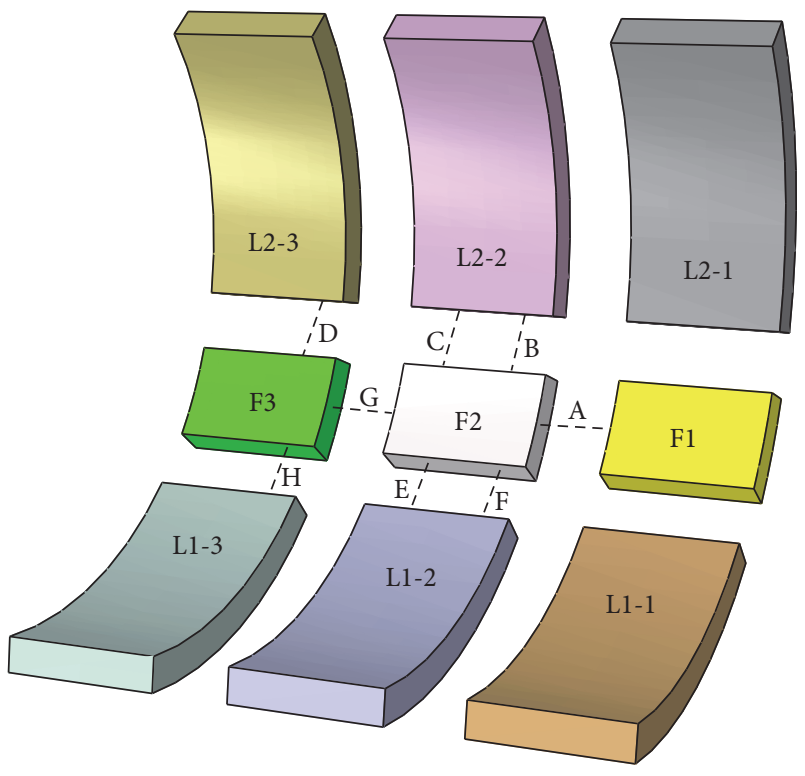

FIGURE 11: Schematic diagram of the bolt failure position.

proposed FE model of the shield tunnel, and the numerical results are provided in the following section. In particular, the failure characteristics of the joint bolts are carefully discussed in terms of the failure location and the failure sequence.

2.5. Dynamic Analysis Theory and Analysis Parameters. The Hilber-Hughes-Taylor time-integration scheme (the HHT scheme) [30] was used to solve the dynamic problem of tunnel structure under the train impact. The HHT scheme was deduced based on the basic Newmark time-integration scheme and using the implicit algorithm, which was very effective in solving the complicated nonlinear dynamics problems. The d'Alembert dynamics balance equation and the vector equations of displacement and velocity are as follows:

$$
\begin{aligned}
& {[M]\{\ddot{u}\}_{t+\Delta t}+(1+\alpha)\{[C]\{\dot{u}\}+[K]\{u\}-P\}_{t}} \\
& \quad-\alpha\{[C]\{\dot{u}\}+[K]\{u\}-P\}_{t+\Delta t}=0, \\
& \{u\}_{t+\Delta t}=\{u\}_{t}+\Delta t\{\dot{u}\}_{t} \\
& \quad+\Delta t^{2}\left[\left(\frac{1}{2}-\beta\right)\{\ddot{u}\}_{t}+\beta\{\ddot{u}\}_{t+\Delta t}\right], \\
& \{\dot{u}\}_{t+\Delta t}=\{\dot{u}\}_{t}+\Delta t\left[(1-\gamma)\{\dot{u}\}_{t}+\gamma\{\ddot{u}\}_{t+\Delta t}\right],
\end{aligned}
$$

where $[M]$ is the mass matrix, $[C]$ is the damping matrix, $[K]$ is the stiffness matrix, $[P]$ is the train impact load, $[u]_{t},[\dot{u}]_{t}$, and $[\ddot{u}]_{t}$ are the displacement increment, velocity increment, and acceleration increment, respectively, $\alpha$ is the weight factor, and $\beta$ and $\gamma$ are the adjustable parameters based on the requirements of the integral precision and stability of calculation.

The HHT method possesses advertised stability, and the order properties provide $\alpha \in(-1 / 3,0), \beta=\left(1-\alpha^{2}\right) / 4$, and $\gamma=1 / 2-\alpha$. Reducing $\alpha$ value will lead to larger damping in the numerical solution, while there will be no damping when $\alpha=0$ [30].

The wall-clock time for the numerical simulation of the proposed model with the train running speed of $200 \mathrm{~km} / \mathrm{h}$ was $31.50 \mathrm{~ms}$, which was determined by the duration time of the impact load. As he implicit HHT scheme was highly stable for any time step and the time step was dependent on the highest frequency of the model structure, the increment of the time step was automatically determined based on the computational results of the previous step and the frequency of the model structure. Thus, there was no limitation of the stable time increment, and it was not necessary for the time step length to be fixed.

\section{Failure Characteristics of Joint Bolts}

In the numerical analysis, the damage variables of eight bolts, two longitudinal bolts ( $A$ and $G$ ) and six circumferential bolts (B, C, D, E, F, and H), were observed reaching 1 (see Figure 12) in all the 108 bolts considered in the proposed model (named Model I). The above observations indicated that these bolts exhibited failure under the HST impact load. Figure 11 shows a clear distribution of the failure location of the joint bolts. Obviously, the failure bolts are mainly distributed around the target segment (F2), as shown in Figure 11.

The failure sequence of each bolt with accurate failure time is summarized in Table 4, which shows that the failure location has a significant influence on the failure sequence. As shown in Table 4, the bolt failure in the tunnel lining generally occurs in sequence along the travelling direction of the HST. Based on the failure sequence, the eight bolts are divided into two groups, $\mathrm{A}$ and $\mathrm{B}$, with five and three bolts, respectively. The five bolts in Group A are all directly connected with the target segment (F2), and the failure of these bolts happens between $4.02 \mathrm{~ms}$ (bolt A) and $6.14 \mathrm{~ms}$ (bolt C). On the other hand, in Group B, the three bolts are all connected with segment F3, and the failure happens between $15.45 \mathrm{~ms}$ (bolt $\mathrm{G}$ ) and $17.31 \mathrm{~ms}$ (bolt $\mathrm{H}$ ). It is clearly shown in Table 5 that failure firstly happens at bolt $\mathrm{A}$, and the failure of the last three bolts (Group B) happens almost 9.0 ms later than the first five bolts in Group A.

The tensile and shear force time history curves of the eight failure bolts are illustrated in Figures 13 and 14, respectively. 


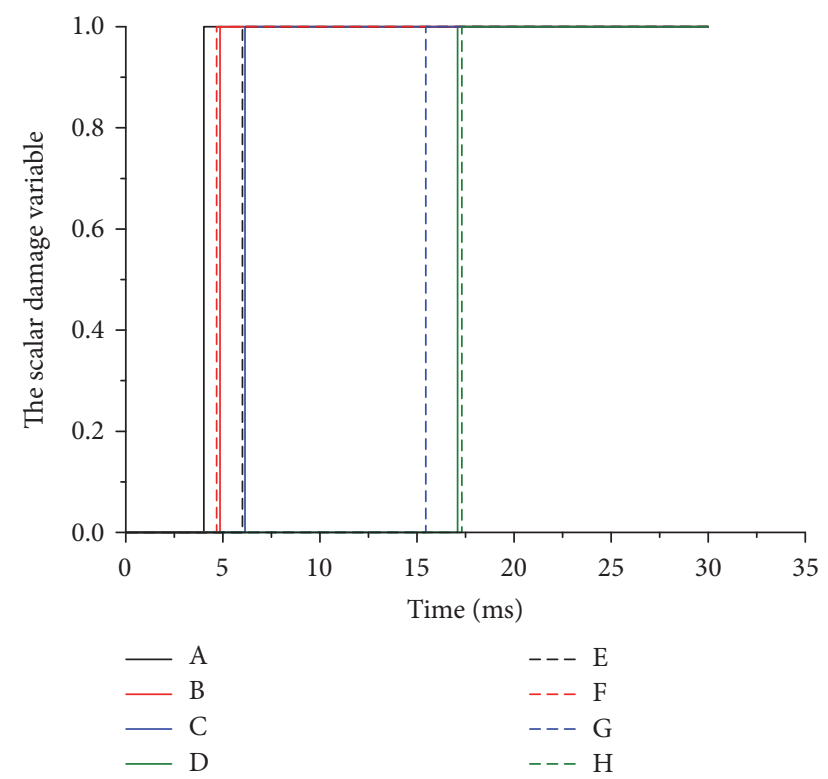

FIGURE 12: The scalar damage variable versus time curves for eight failure bolts.

TABLE 5: Failure time and sequence of joints bolts.

\begin{tabular}{lcc}
\hline Failure sequence & Joint bolt number & Failure time $(\mathrm{ms})$ \\
\hline 1 & $\mathrm{~A}$ & 4.02 \\
2 & $\mathrm{~F}$ & 4.68 \\
3 & $\mathrm{~B}$ & 4.85 \\
4 & $\mathrm{E}$ & 6.01 \\
5 & $\mathrm{C}$ & 6.14 \\
6 & $\mathrm{G}$ & 15.45 \\
7 & $\mathrm{D}$ & 17.09 \\
8 & $\mathrm{H}$ & 17.31 \\
\hline
\end{tabular}

As shown in Figure 13, the tensile forces of bolts A, B, and $\mathrm{F}$ increase rapidly from $0 \mathrm{~ms}$ and drop to zero immediately after reaching each maximum value at each failure time (see Table 4), but the maximum tensile force of bolt $\mathrm{A}$ is significantly larger than that of bolts $\mathrm{B}$ and $\mathrm{F}$. The tensile forces of bolts $\mathrm{E}$ and $\mathrm{H}$ increase instantly to the maximum values after $0 \mathrm{~ms}$ and decrease gradually to about $47 \mathrm{kN}$, respectively, until failure happens, where a sudden drop of the tensile force occurs in both of the bolts. The tensile forces of bolts C, D, and G keep equal to zero, which indicates that these bolts are always under compression during the whole impact loading process. In Figure 14, the shear force of bolt A inclines gradually to its maximum value (about $65 \mathrm{kN}$ ) and decreases to about $40 \mathrm{kN}$ until reaching the failure time $(4.02 \mathrm{~ms})$, where a sudden drop to zero is observed. The shear forces of bolts B, C, D, E, F, and $\mathrm{H}$ increase in a fluctuant manner from zero to the maximum values (all equal to $478.5 \mathrm{kN}$ ) and drop suddenly to zero at each failure time (see Table 4). The shear force of bolt $G$ is equal to zero until $11 \mathrm{~ms}$ and then starts to increase rapidly to the maximum value $(478.5 \mathrm{kN})$, where a sudden drop is also observed after reaching the failure time. Obviously, sudden drops to zero are observed in all the eight bolts in terms of tensile or shear force. This indicates that instant bolt failure happens in all the eight bolts, and the bolt can no longer bear any more load once the bolt failure happens. Particularly, the shear force time history curves of bolts B and F are observed to be very similar, which is possible due to the symmetric feature of the two bolts with respect to the impact loading center. Similar shear force time history curves are also found in the failure behavior of bolts $\mathrm{C}$ and $\mathrm{D}$ and bolts $\mathrm{D}$ and $\mathrm{H}$.

In Table 6, the maximum tensile and shear forces of the failure bolt and the failure time of each bolt in the impact process are summarized. The maximum tensile force $(652.8 \mathrm{kN})$ was observed in bolt $\mathrm{A}$, while the maximum shear force $(478.5 \mathrm{kN})$ was observed in bolts B-H. Meanwhile, the failure type for each bolt was obtained as instant complete damage based on the observed failure behavior. It was found that the number of bolts that failed due to shear failure was far more than those that failed due to tensile failure.

In order to investigate the influence of bolt failure on the mechanical behavior of the joint bolt, another FE model (named Model II) of the shield tunnel without considering the bolt failure was established for comparisons. The tensile and shear force time history curves of eight bolts $\mathrm{A}-\mathrm{H}$ (in the same positions of Model I) obtained from Model II are shown in Figures 15 and 16, respectively. As shown in Figure 15, the tensile force of bolt A increases to about $3400 \mathrm{kN}$ at $19.22 \mathrm{~ms}$ and decreases to about $2700 \mathrm{kN}$ at the end of the impact loading process. The tensile forces of bolts $\mathrm{E}, \mathrm{F}$, and $\mathrm{H}$ are observed to be increasing with fluctuation during the whole impact loading process, while the tensile forces of bolts $\mathrm{B}, \mathrm{C}$, $D$, and $G$ almost keep equal to zero. In Figure 16, the shear forces of bolts A-H are observed to be increasing gradually to the maximum values and then to be decreasing stably (without reaching zero) until the end of the impact loading process. In particular, the time history curves of tensile and shear forces of all the eight bolts are completely consistent with those obtained in Model I between $0 \mathrm{~ms}$ and $4.02 \mathrm{~ms}$, while, after $4.02 \mathrm{~ms}$, the curves are totally different between the two models. Table 7 shows the maximum tensile and shear forces for each failure bolt and the respective time in the impact process. As shown in the table, the maximum tensile force $(3422.7 \mathrm{kN})$ is found in bolt A in Model II, which is 5.24 times larger than the ultimate tensile force of bolt $(652.8 \mathrm{kN})$ found in bolt A in Model I. The maximum shear force $(1624.4 \mathrm{kN})$ is found in bolt E in Model II, which is 3.39 times larger than the ultimate shear force of bolt $(478.5 \mathrm{kN})$ found in bolts B-H in Model I. The maximum tensile and shear forces observed in Model II are substantially larger than the respective ultimate bearing capacities of the joint bolt, which is not realistic. This indicates that the bolt failure has a significant influence on the ultimate bearing capacity and the mechanical behavior of the segmental joints. From the practical point of view, there is no doubt that the bolt failure indeed happens under the HST impact load, which means that the bolt failure cannot be ignored in the FE model of the shield tunnel. 


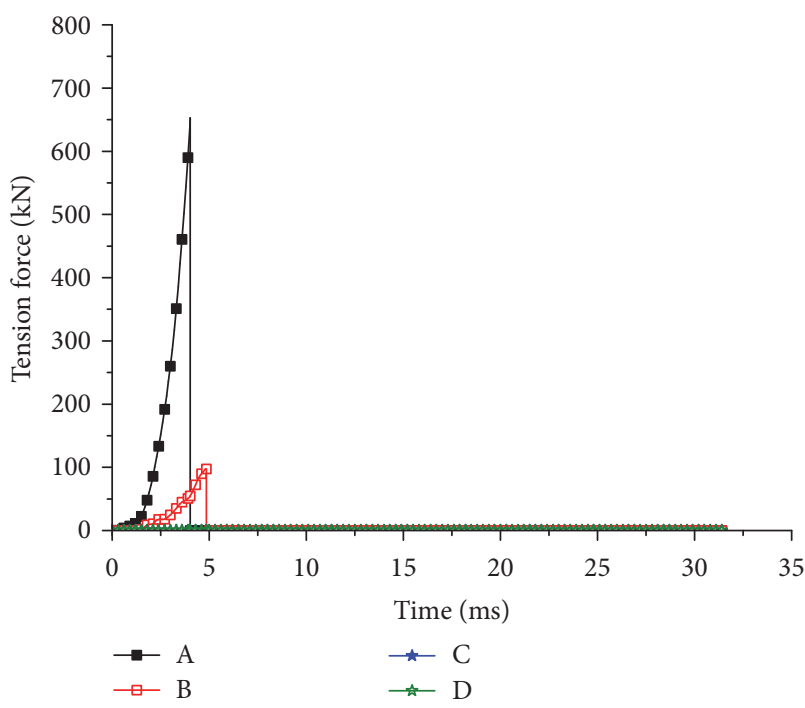

(a)

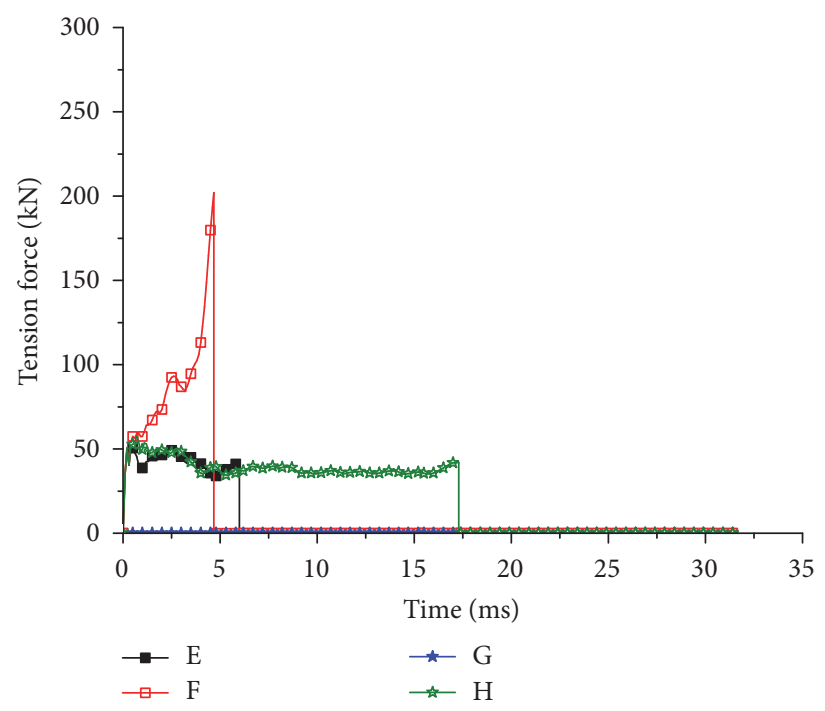

(b)

Figure 13: The tensile force time history curves for (a) bolts A, B, C, and D and (b) bolts E, F, G, and H in Model I.

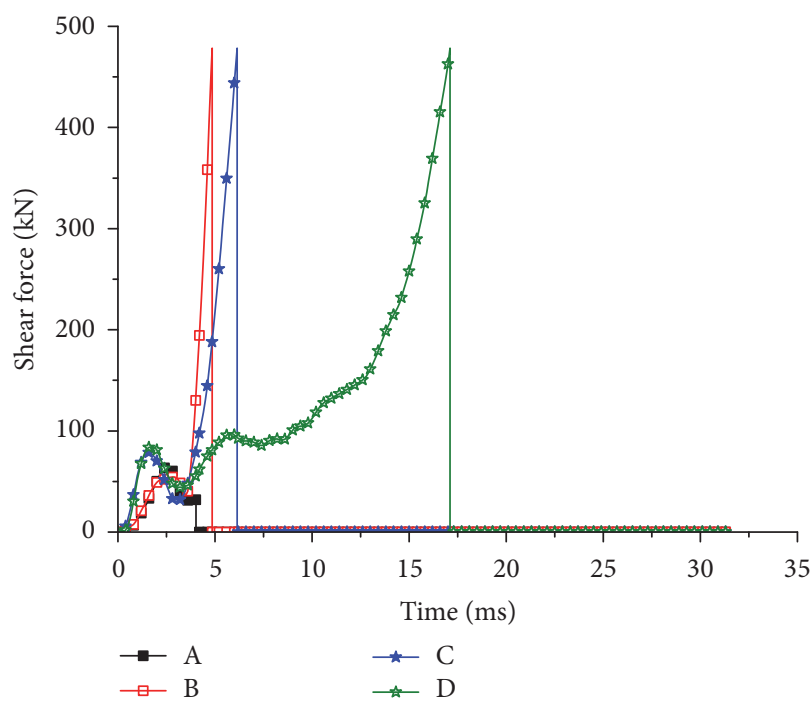

(a)

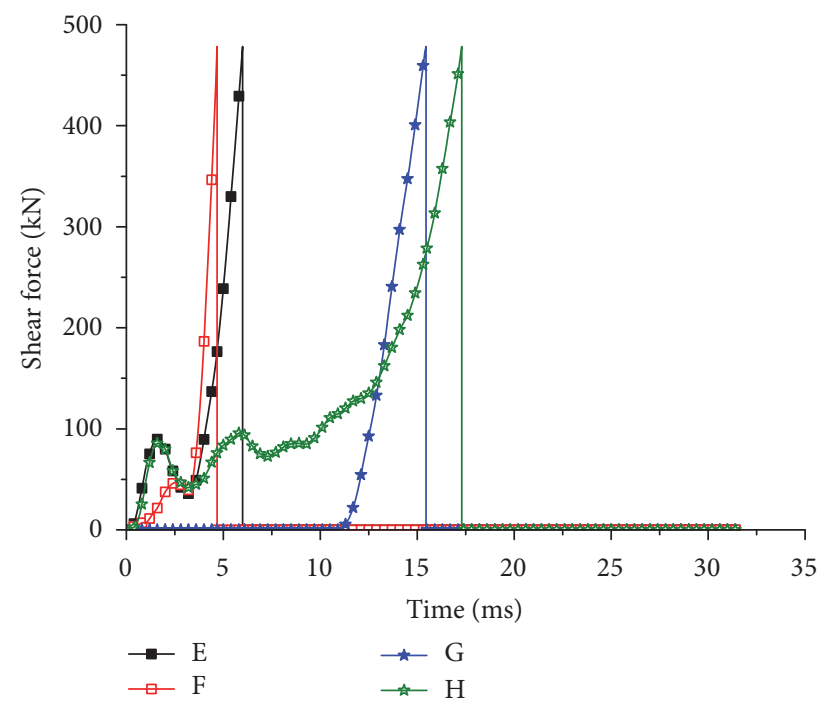

(b)

Figure 14: The shear force time history curves for (a) bolts A, B, C, and D and (b) bolts E, F, G, and H in Model I.

\section{Influence of Bolt Failure on the Dynamic Responses of Tunnel Segments}

The influence of bolt failure on the dynamic responses of tunnel segments was examined in terms of the segment damage behavior and segment displacement conditions as follows.

4.1. Segment Damage Behavior. In [31], the damage behavior of the concrete tunnel lining was defined as the isotropic elastic damage together with the isotropic tensile and compressive plastic theory.
It is shown in the theory that when the concrete lining is under tension,

$$
\begin{aligned}
& d_{t}=1-\frac{1.2-0.2 x^{5}}{1.2}, \quad x \leq 1, \\
& d_{t}=1-\frac{1}{1.2\left[\alpha_{t}(x-1)^{1.7}+x\right]}, \quad x>1,
\end{aligned}
$$

where $d_{t}$ is the tension damage factor; $x=\varepsilon_{t} / \varepsilon_{f t}$, in which $\varepsilon_{f t}=65 f_{t}^{0.54} \times 10^{-6}$ is the peak tension strain corresponding to the peak tension stress; $\alpha_{t}=0.312 f_{t}^{2}$; and $f_{t}$ is the peak tension stress. 
TABLE 6: Maximum tensile and shear force and the failure type of joint bolts in Model I.

\begin{tabular}{|c|c|c|c|c|c|c|c|c|}
\hline Joint bolt number & $\mathrm{A}$ & B & $\mathrm{C}$ & $\mathrm{D}$ & $\mathrm{E}$ & $\mathrm{F}$ & G & $\mathrm{H}$ \\
\hline Maximum tensile force $(\mathrm{kN})$ & 652.8 & 97.6 & 0.0 & 0.0 & 50.5 & 202.7 & 0.0 & 57.6 \\
\hline Time of maximum tensile force (ms) & 4.02 & 4.85 & 1 & I & 0.52 & 4.68 & I & 0.72 \\
\hline Maximum shear force $(\mathrm{kN})$ & 65.51 & 478.5 & 478.5 & 478.5 & 478.5 & 478.5 & 478.5 & 478.5 \\
\hline Time of maximum shear force (ms) & 2.60 & 4.85 & 6.14 & 17.09 & 6.01 & 4.68 & 15.45 & 17.31 \\
\hline Failure type & Tensile & Shear & Shear & Shear & Shear & Shear & Shear & Shear \\
\hline
\end{tabular}

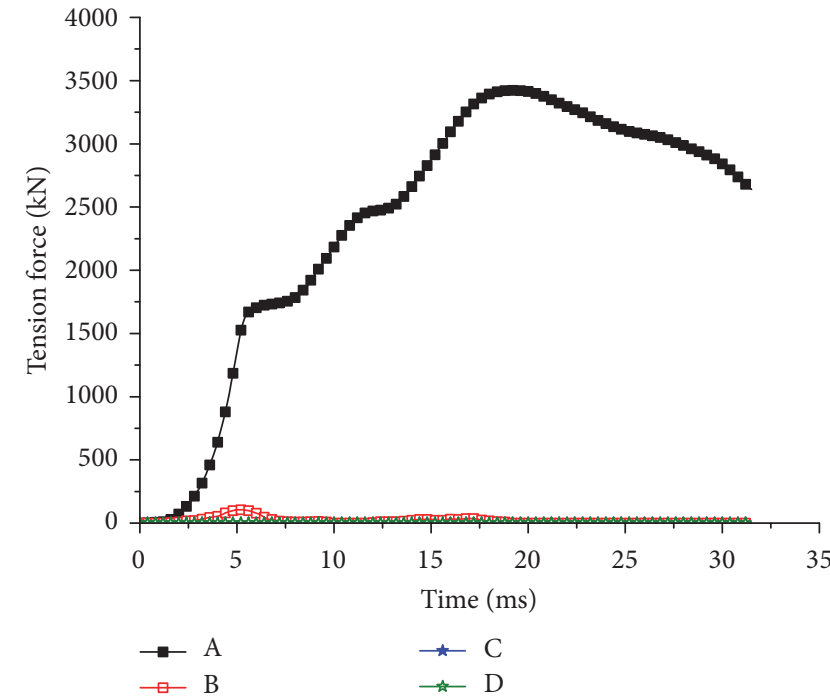

(a)

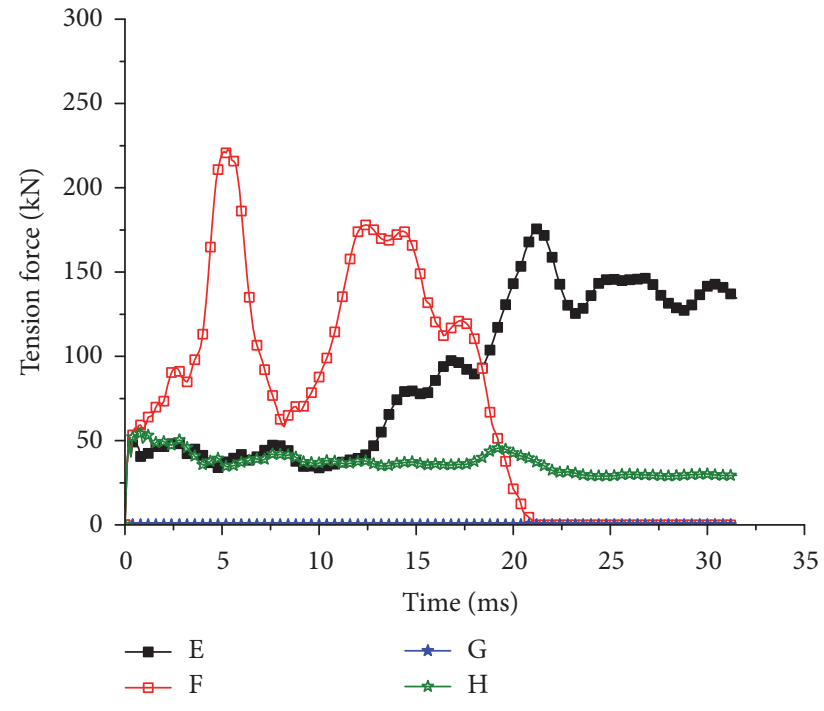

(b)

FIGURE 15: The tensile force time history curves for (a) bolts A, B, C, and D and (b) bolts E, F, G, and H in Model II.

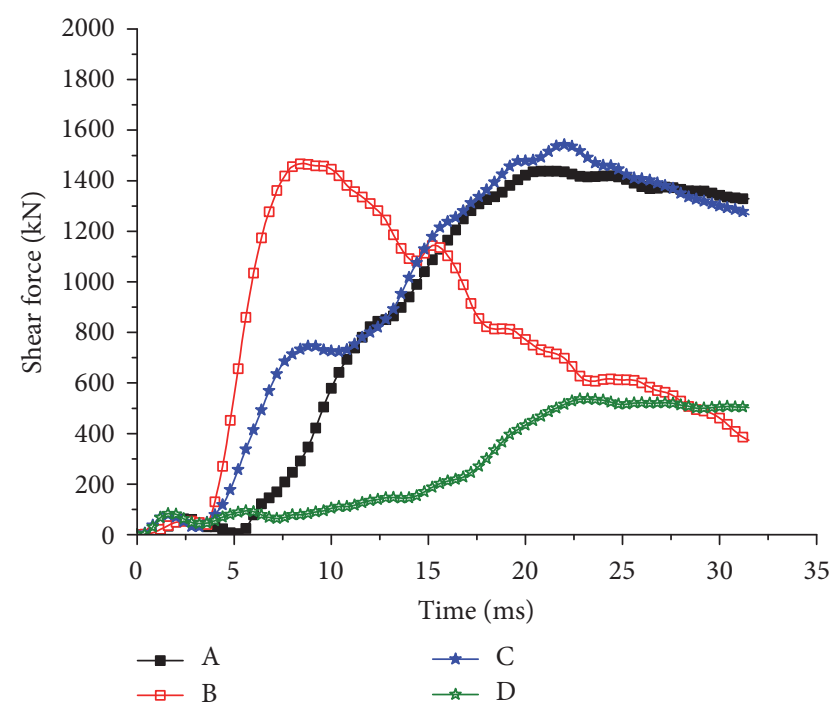

(a)

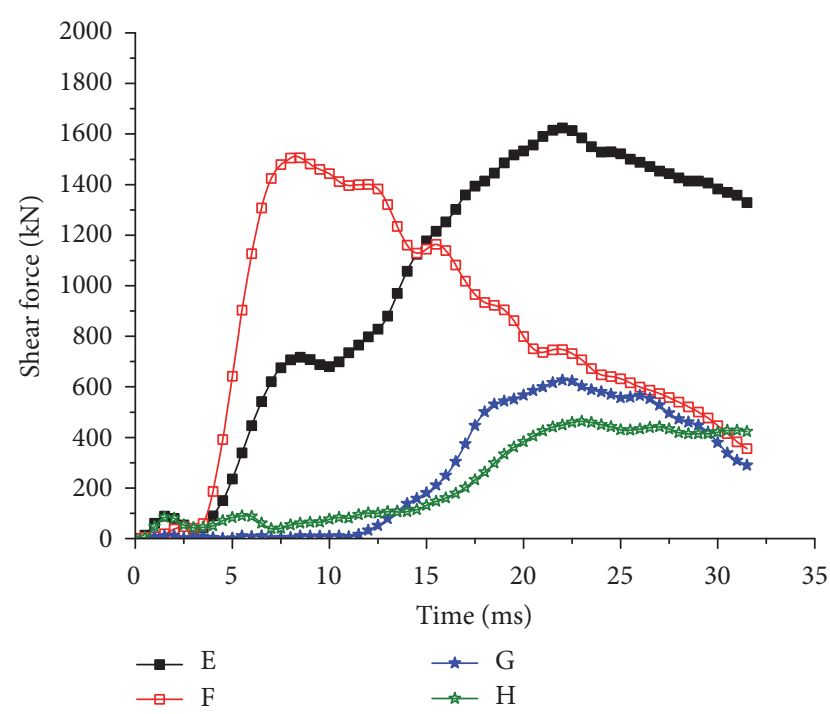

(b)

Figure 16: The tensile force time history curves for (a) bolts A, B, C, and D and (b) bolts E, F, G, and H in Model II. 
TABLE 7: Maximum tensile and shear forces and the failure type of joint bolts in Model II.

\begin{tabular}{|c|c|c|c|c|c|c|c|c|}
\hline Joint bolt number & A & $\mathrm{B}$ & $\mathrm{C}$ & $\mathrm{D}$ & $\mathrm{E}$ & $\mathrm{F}$ & G & $\mathrm{H}$ \\
\hline Maximum tensile force $(\mathrm{kN})$ & 3422.7 & 105.8 & 0.0 & 0.0 & 175.8 & 222.8 & 0.0 & 57.6 \\
\hline Time of maximum tensile force (ms) & 19.22 & 5.14 & l & l & 21.33 & 5.30 & l & 0.72 \\
\hline Maximum shear force $(\mathrm{kN})$ & 1438.2 & 1468.4 & 1541.8 & 536.3 & 1624.4 & 1512.1 & 627.3 & 464.3 \\
\hline Time of maximum shear force (ms) & 20.81 & 8.63 & 21.87 & 23.09 & 21.97 & 8.24 & 22.08 & 22.89 \\
\hline
\end{tabular}

When the concrete is under compression,

$$
\begin{aligned}
& d_{c}=1-\frac{1}{\alpha_{a}}\left[\alpha_{a}+\left(3-2 \alpha_{a}\right) x+\left(\alpha_{a}-2\right) x^{2}\right] \quad x \leq 1, \\
& d_{c}=1-\frac{1}{\alpha_{a}\left[\alpha_{d}(x-1)^{2}+x\right]} \quad x>1,
\end{aligned}
$$

where $d_{c}$ is the compression damage factor; $x=\varepsilon_{c} / \varepsilon_{f c}$, in which $\varepsilon_{f c}=\left(700+172 \sqrt{f_{c}}\right) \times 10^{-6}$ is the peak compressive strain corresponding to the peak compressive stress; $\alpha_{a}=$ $2.4-0.0125 f_{c} ; \alpha_{d}=0.157 f_{c}^{0.785}-0.905$; and $f_{c}$ is the peak compressive stress.

The ultimate strength, elastic modulus, and Poisson's ratio for the concrete material of the tunnel lining are C50, $34.5 \mathrm{GPa}$, and 0.2 , respectively. The relationships between stress and nonplastic strain, the damage factor, and the inelastic strain of the concrete in plastic stage are obtained in [15].

As the segments were always under compression under the HST impact load, the investigation of the structural behavior of the shield tunnel was mainly focused on the compressive damage of the intrados of the segment lining. Figure 17 shows the compressive damage contours on the intrados of the tunnel lining obtained in both Models I and II. It can be found in the figure that the compressive damage is mainly distributed on the target segment (F2) and its adjacent segments. The compressive damage was observed to be not very significant in other segments. Obviously, as shown in Figure 17, the compressive damage distribution in the longitudinal direction is significantly larger than that in the circumferential direction. Under the impact load from a derailed train running at a speed of $200 \mathrm{~km} / \mathrm{h}$, the maximum compressive damage factor observed in the segments was 0.9869 in Model I, while the factor was 0.9776 in Model II. Although the difference between the two damage factors was not that large, there was a significant difference in the damage distribution on the intrados of the tunnel lining between the two cases. In Model I, the damage area on the intrados of the lining was $7.98 \mathrm{~m}^{2}$, while the damage area in Model II was $10.36 \mathrm{~m}^{2}$, which increased by approximately $30 \%$ compared with Model I.

Moreover, the damage evolution of the shield tunnel under the HST impact load was also examined via checking the compressive damage variable of each monitoring point (see Figure 4) in both Models I and II. The compressive damage variable values for all the fifteen monitoring points in Models I and II (with and without considering the influence of bolt failure) are shown in Figure 18. In Model I, it is found that the compressive damage variable increases slowly from point number 1 to point number 5 and then significantly increases to around 0.9 at point number 6 . After that, the compressive damage variable keeps at a maximum value around 0.9 until point number 11 and then subsequently drops to around 0.1 and 0 at point number 13 and point number 15, respectively. In Model II, the variation of the compressive damage variable is almost the same as the variation in Model I, and the compressive damage variable also reaches the maximum value of around 0.9 at point number 6. However, compared to Model I, there is no significant increase between point number 5 and point number 6 in Model II. This shows that the influence of bolt failure on the compressive damage behavior of the tunnel lining near the impact center (between points number 6 to number 11) is not significant. On the contrary, the influence of bolt failure on the tunnel linings with little compressive damage occurring is relatively larger (i.e., the region between points number 1 to number 5 and number 12 to number 13 ).

4.2. Segment Displacement. The displacement contours of the tunnel segments in both Model I and Model II are shown in Figure 19. As shown in the figure, the final displacement of the tunnel segment is mainly observed on the intrados of the target segment (F2) and its adjacent segments. It also shows that the displacement distribution area along the longitudinal direction is larger than that along the circumferential direction. The maximum final displacement of the segment in Model I is $6.206 \mathrm{~cm}$, while that displacement in Model II is $4.135 \mathrm{~cm}$ with a reduction of about $33.3 \%$. This is possibly due to the fact that the constraints of the joint bolts to the segment displacement disappear after the bolt failure happens in Model I, while those constraints do not disappear in Model II as the bolt failure is not considered there.

The final displacement values of the tunnel segments for all the monitoring points in both Modes I and II are shown in Figure 20. In both of the models, the segment displacement starts to increase from point number 1 , reaches the maximum value near the impact loading center (at point number 8 ), and then decreases to 0 at point number 15 . This indicates that the farther away from the impact loading center the segment is, the smaller the segment displacement observed is. Besides, it is found that the segment displacement values of monitoring points numbers 6-15 in Model I were generally larger than the displacement values in Model II. On the contrary, the displacement values of monitoring points numbers $1-5$ behind the impact center (along the travelling direction of 


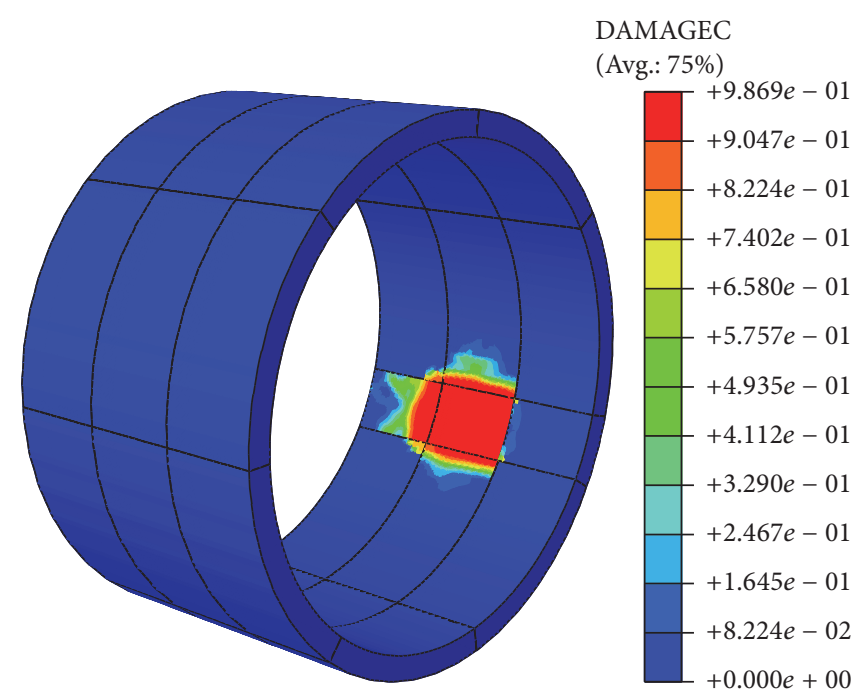

(a)

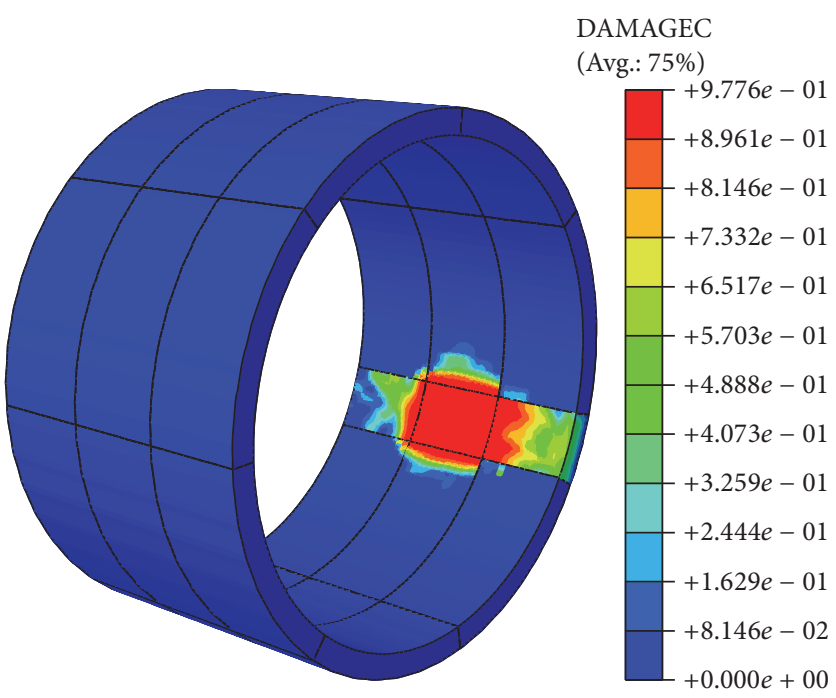

(b)

FIGURE 17: Compressive damage contours of the lining intrados in (a) Model I and (b) Model II.

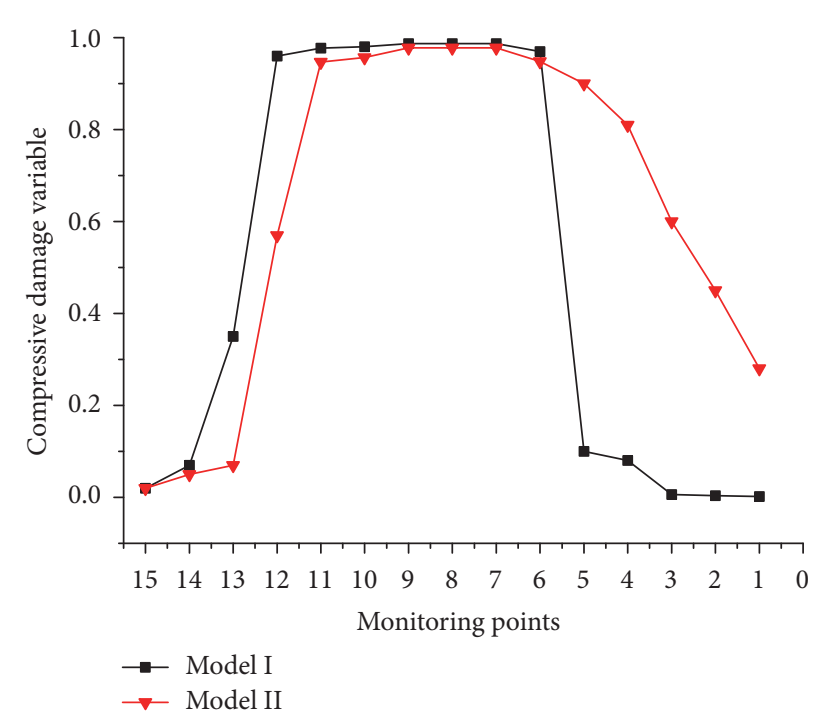

FIGURE 18: Compressive damage variable at each monitoring point.

the train) in Model I were smaller than the displacement values in Model II. This is possibly due to the fact that the impact loading applied on segment F2 is not able to effectively transmit from the bolts to segment F1 after the bolt failure happens.

\section{Influence of Train Speed on the Bolt Failure}

In order to investigate the influence of the train speed on the failure characteristics of the joint bolts, three different impact loads obtained from different running speeds, $200 \mathrm{~km} / \mathrm{h}$, $250 \mathrm{~km} / \mathrm{h}$, and $300 \mathrm{~km} / \mathrm{h}$, are applied on the intrados of the target segment F2, respectively. It was observed that the wallclock times for the numerical simulation of the proposed FE model with the train running speeds of $200 \mathrm{~km} / \mathrm{h}, 250 \mathrm{~km} / \mathrm{h}$, and $300 \mathrm{~km} / \mathrm{h}$ were $31.50 \mathrm{~ms}, 33.75 \mathrm{~ms}$, and $34.50 \mathrm{~ms}$, respectively. As the impact load was applied on the target segment F2 directly, the failure characteristics of bolts A, B, C, E, F, and $\mathrm{G}$ connected to the segment F2 were carefully studied. The time history curves of the tensile and shear forces of the six bolts at train running speeds of $200 \mathrm{~km} / \mathrm{h}, 250 \mathrm{~km} / \mathrm{h}$, and $300 \mathrm{~km} / \mathrm{h}$ are illustrated in Figures 21 and 22, respectively.

The time history curves of the six bolts with $250 \mathrm{~km} / \mathrm{h}$ and $300 \mathrm{~km} / \mathrm{h}$ train speed show a similar trend to the time history curves of the six bolts with $200 \mathrm{~km} / \mathrm{h}$ train speed (mentioned in Section 3). Under the three different impact loading conditions (which represents three different train running speeds), failure was observed in all the six bolts. The failure type, failure time, and failure sequence of the six bolts obtained from three different train running speeds are listed in Table 8. It is found that the failure type of the bolt on the same position is consistent even with different train running speeds. Besides, it is observed that tensile failure occurs in bolt A, while shear failure occurs in bolts B, C, E, F, and G, regardless of the impact loading conditions. This indicates that changing the running speed of the train has no influence on the failure type and the trend of the tension and shear forces time history curves.

On the contrary, it is observed that changing the train running speeds can result in different failure time for the six bolts. As shown in Table 8, the six bolts are generally divided into two groups according to the failure time. In the first group (bolts A, B, C, E, and F), the bolt failure time is within the range of $3.28 \mathrm{~ms}-6.14 \mathrm{~ms}$, while the failure time of the second group (bolt G) is within the range of $11.75 \mathrm{~ms}-$ $15.45 \mathrm{~ms}$, which is almost $9.0 \mathrm{~ms}$ later than the first group. Besides, it is observed that the failure time of the bolt on the same position is not consistent. The bolt failure time is reduced by increasing the train running speed. The average failure times of the six bolts according to three different train speeds $(200 \mathrm{~km} / \mathrm{h}, 250 \mathrm{~km} / \mathrm{h}$, and $300 \mathrm{~km} / \mathrm{h})$ are $6.86 \mathrm{~ms}$, 
TABLE 8: Bolt failure behavior under different train running speeds.

\begin{tabular}{|c|c|c|c|c|c|c|c|c|c|}
\hline \multirow{2}{*}{ Joint bolt number } & \multicolumn{3}{|c|}{ Failure type } & \multicolumn{3}{|c|}{ Failure time } & \multicolumn{3}{|c|}{ Failure sequence } \\
\hline & $200 \mathrm{~km} / \mathrm{h}$ & $250 \mathrm{~km} / \mathrm{h}$ & $300 \mathrm{~km} / \mathrm{h}$ & $200 \mathrm{~km} / \mathrm{h}$ & $250 \mathrm{~km} / \mathrm{h}$ & $300 \mathrm{~km} / \mathrm{h}$ & $200 \mathrm{~km} / \mathrm{h}$ & $250 \mathrm{~km} / \mathrm{h}$ & $300 \mathrm{~km} / \mathrm{h}$ \\
\hline A & Tensile & Tensile & Tensile & 4.02 & 3.65 & 3.28 & 1 & 1 & 1 \\
\hline B & Shear & Shear & Shear & 4.85 & 4.59 & 4.04 & 3 & 3 & 3 \\
\hline $\mathrm{C}$ & Shear & Shear & Shear & 6.14 & 5.56 & 4.79 & 5 & 5 & 5 \\
\hline $\mathrm{F}$ & Shear & Shear & Shear & 4.68 & 4.40 & 3.89 & 2 & 2 & 2 \\
\hline $\mathrm{E}$ & Shear & Shear & Shear & 6.01 & 5.46 & 4.69 & 4 & 4 & 4 \\
\hline G & Shear & Shear & Shear & 15.45 & 13.52 & 11.75 & 6 & 6 & 6 \\
\hline Average failure time & & & & 6.86 & 6.20 & 5.41 & & & \\
\hline
\end{tabular}

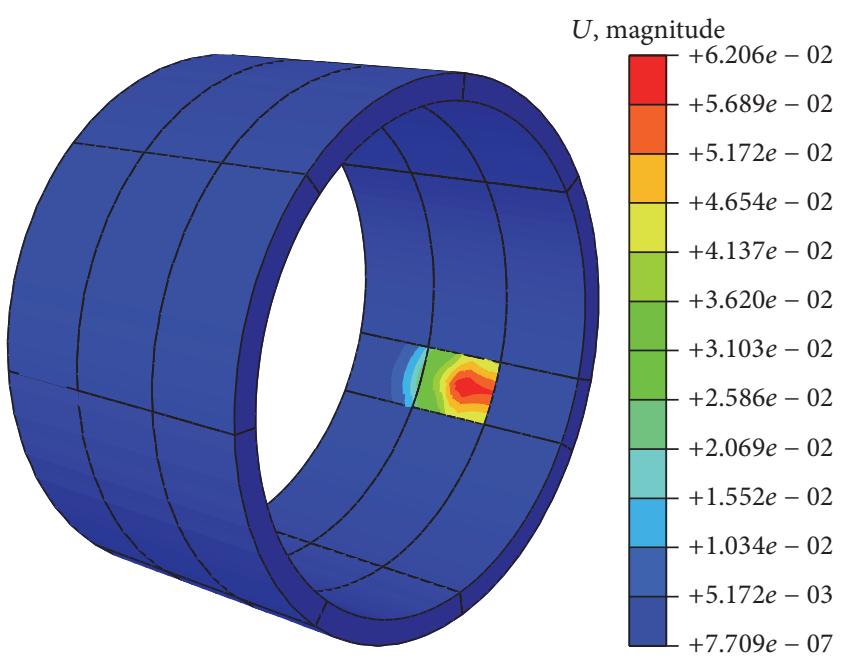

(a)

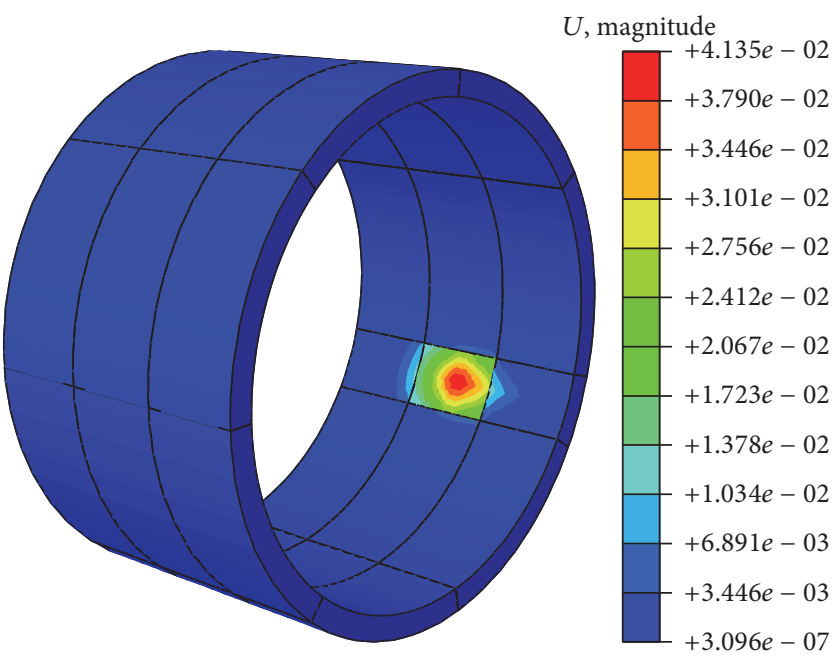

(b)

Figure 19: Displacement contours on the lining intrados in (a) Model I and (b) Model II.

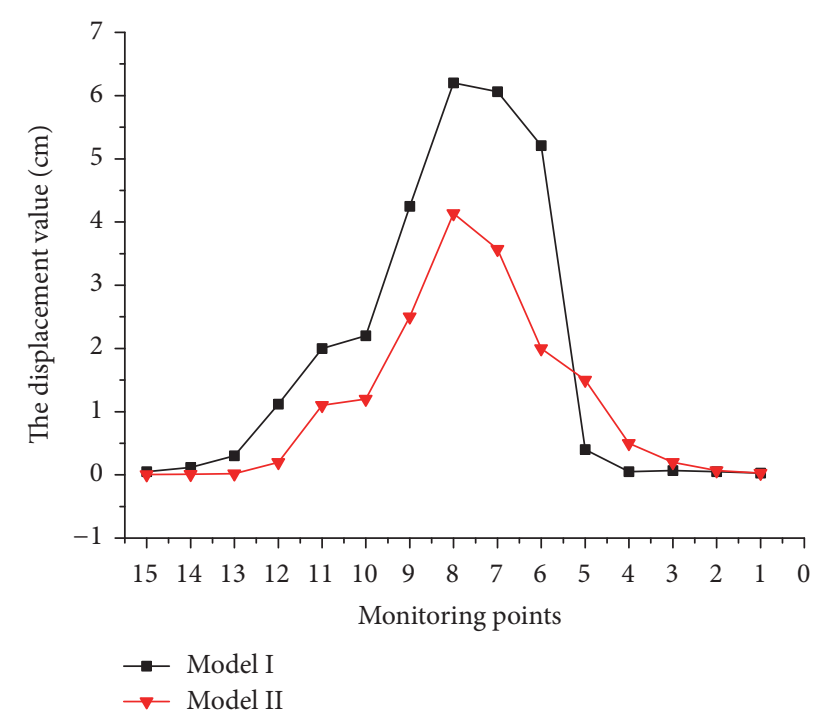

FIGURE 20: Displacement at each monitoring point.

$6.20 \mathrm{~ms}$, and $5.41 \mathrm{~ms}$, respectively. Compared with the case of $200 \mathrm{~km} / \mathrm{h}$, the average failure times in the cases of $250 \mathrm{~km} / \mathrm{h}$ and $300 \mathrm{~km} / \mathrm{h}$ are $0.66 \mathrm{~ms}$ and $1.45 \mathrm{~ms}$ shorter, respectively.
This indicates that bolt failure occurs easier and faster with the increase of the train running speed. Regarding the failure sequence of the six bolts, they are completely consistent under different impact loading conditions, which indicates that the training running speed has a little influence on the bolt failure sequence.

\section{Discussions and Conclusions}

In this paper, a numerical investigation of the failure characteristics of the joint bolt and its influences on the dynamic behavior of the shield tunnel was performed. In this study, an appropriate 3D FE model for a typical shield tunnel considering the bolt failure was proposed. In particular, the "bushing" connector elements were employed to capture the complex characteristics of the joint bolts, while the interface elements were employed to capture the mechanical behavior of the joint surfaces. An impact loading obtained from a HST derailed at a speed of $200 \mathrm{~km} / \mathrm{h}$ with an oblique impact loading angle of $12.5^{\circ}$ provided in [15] was applied on a target segment (F2) in the shield tunnel. The proposed FE model allowed for a realistic response prediction of the shield tunnel under train impacts. The failure characteristics of the joint bolts and the development of segment damage were 

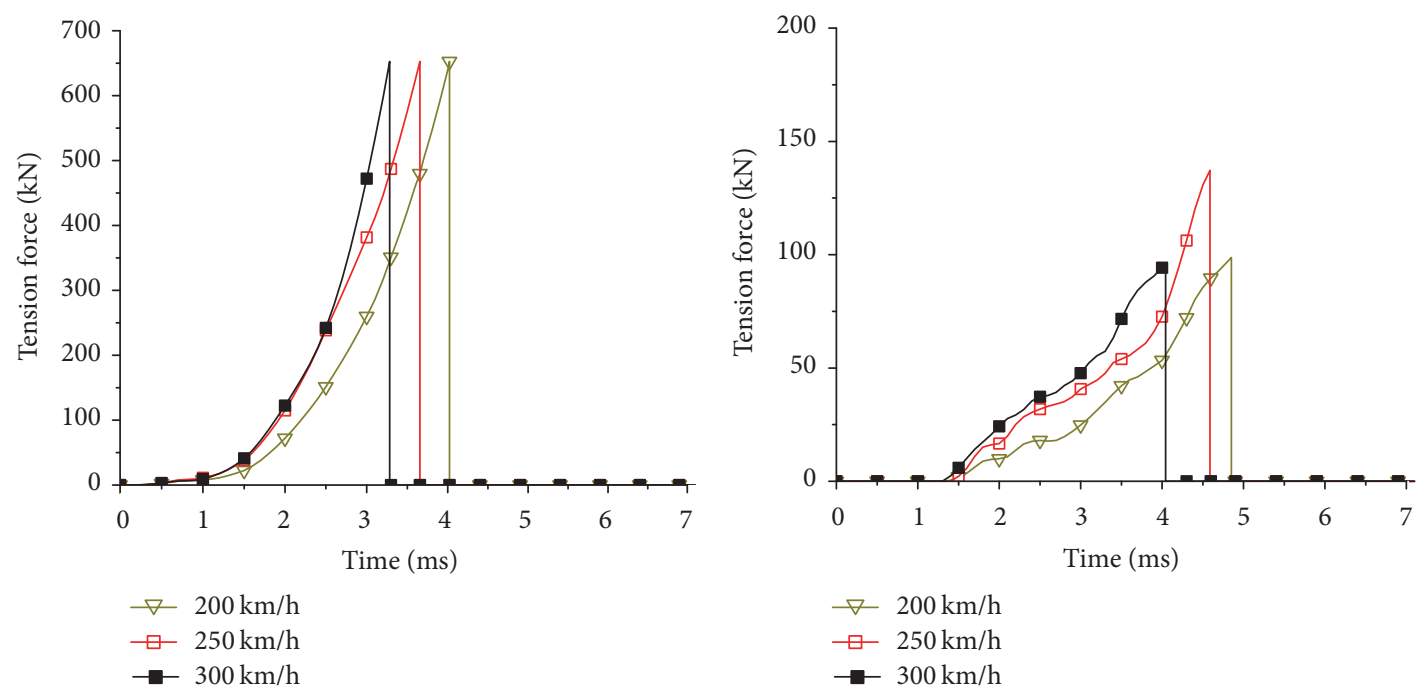

(a) Bolt $\mathrm{A}$
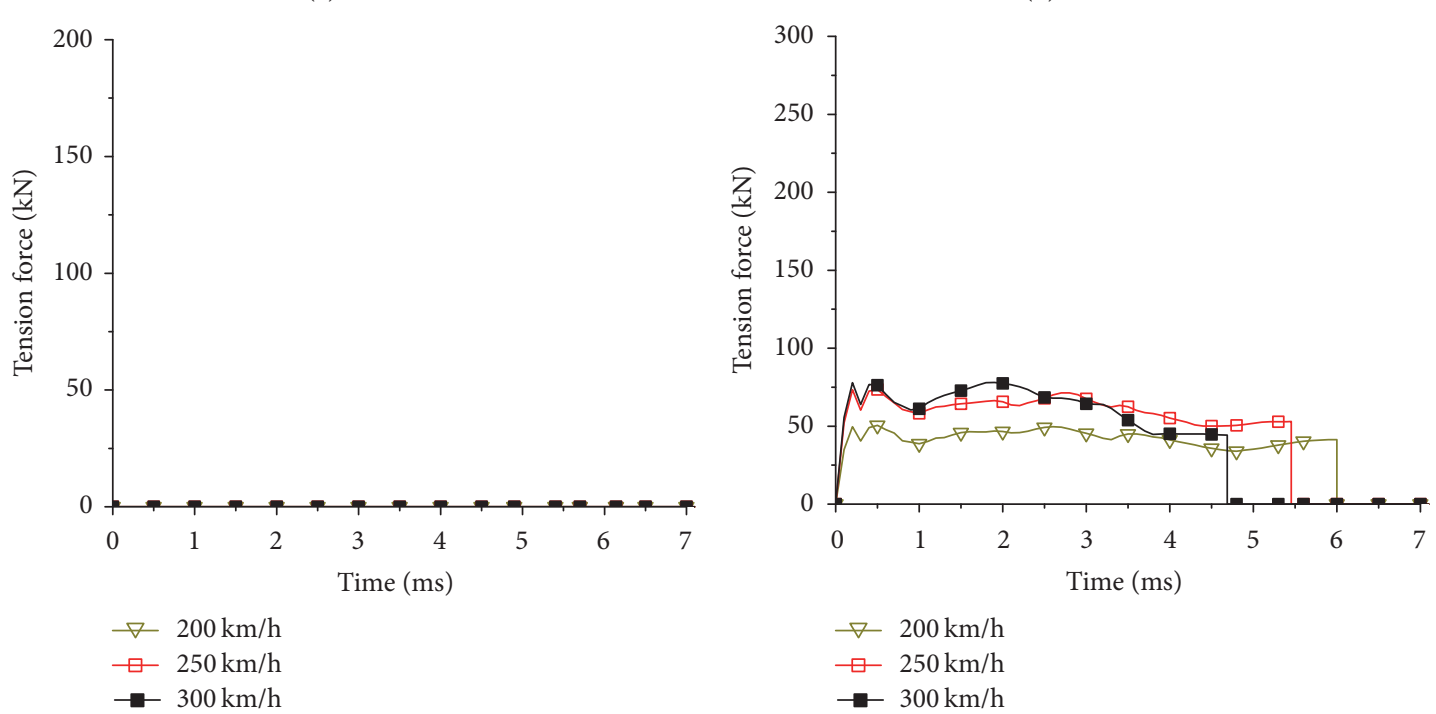

(c) Bolt C

(d) Bolt E
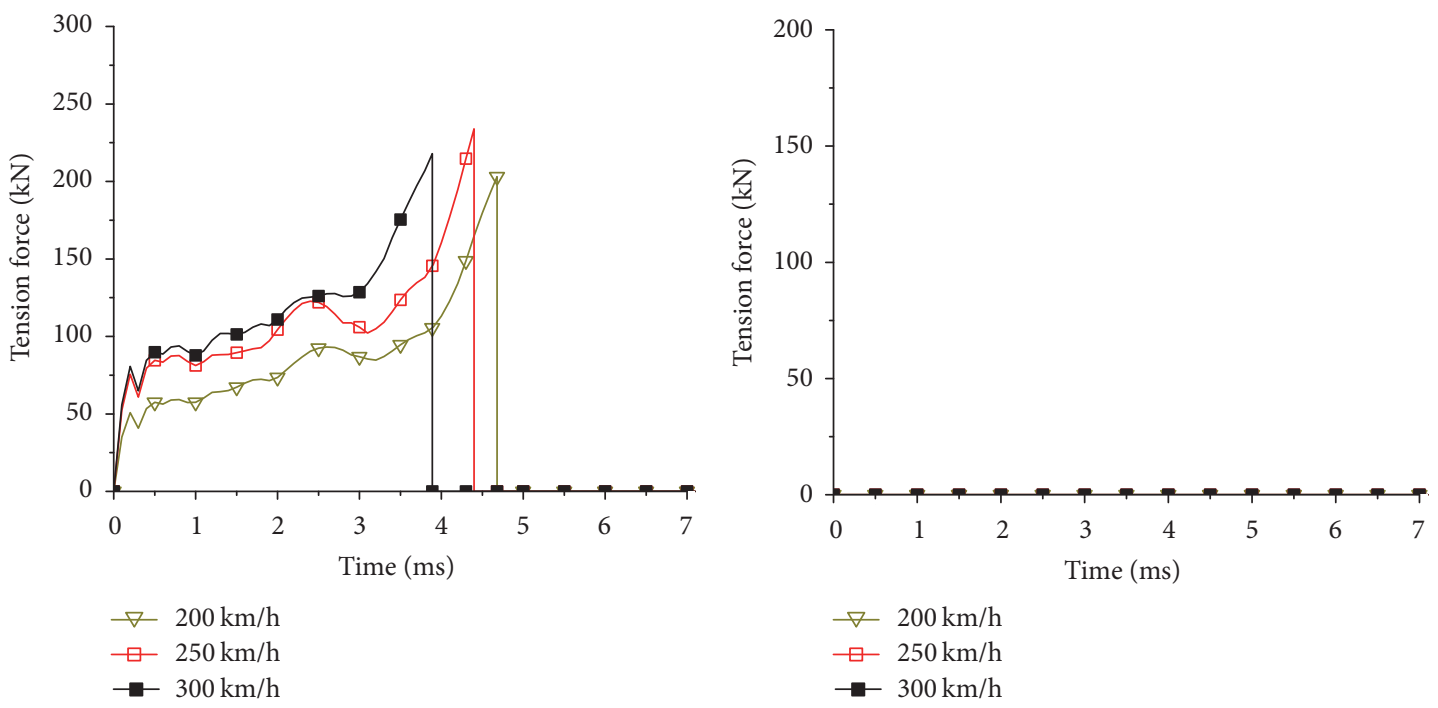

(e) Bolt F

(f) Bolt G

Figure 21: The tensile force time history curves for bolts A, B, C, E, F, and G. 


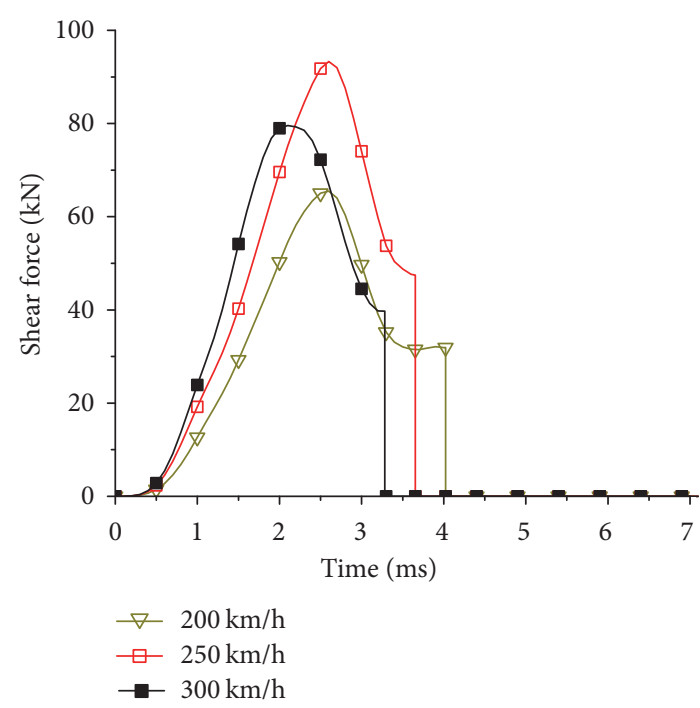

(a) Bolt A

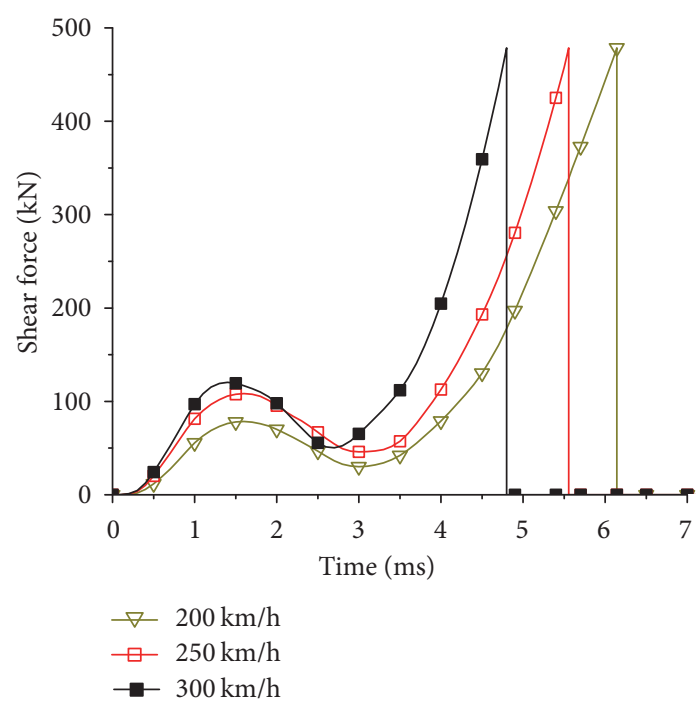

(c) Bolt C

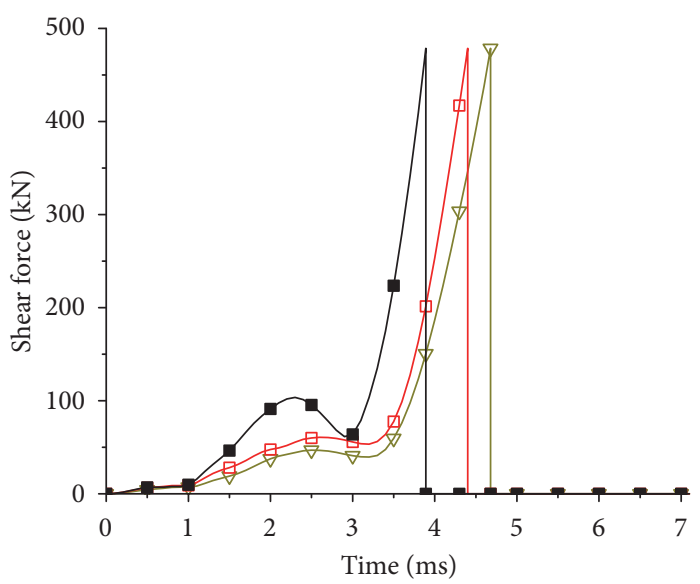

$\nabla-200 \mathrm{~km} / \mathrm{h}$

七 $250 \mathrm{~km} / \mathrm{h}$

- $300 \mathrm{~km} / \mathrm{h}$

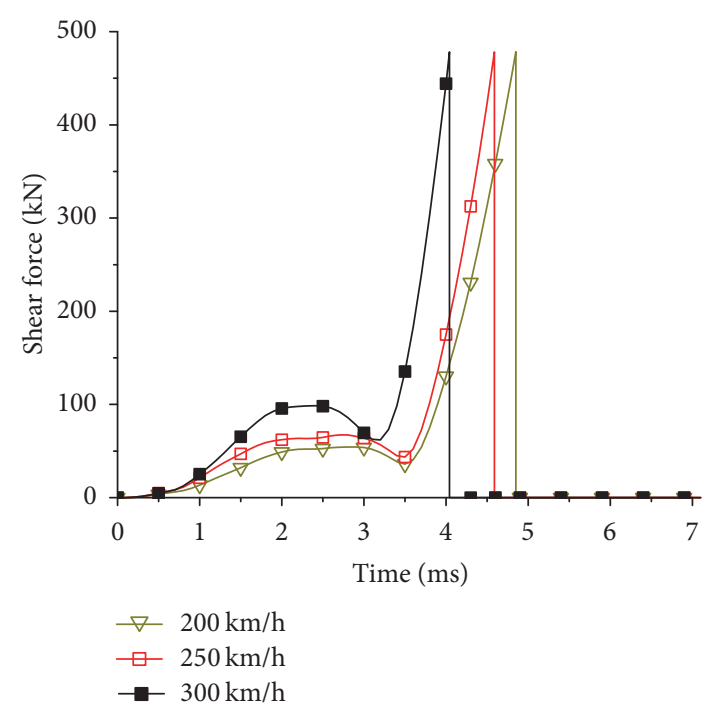

(b) Bolt B

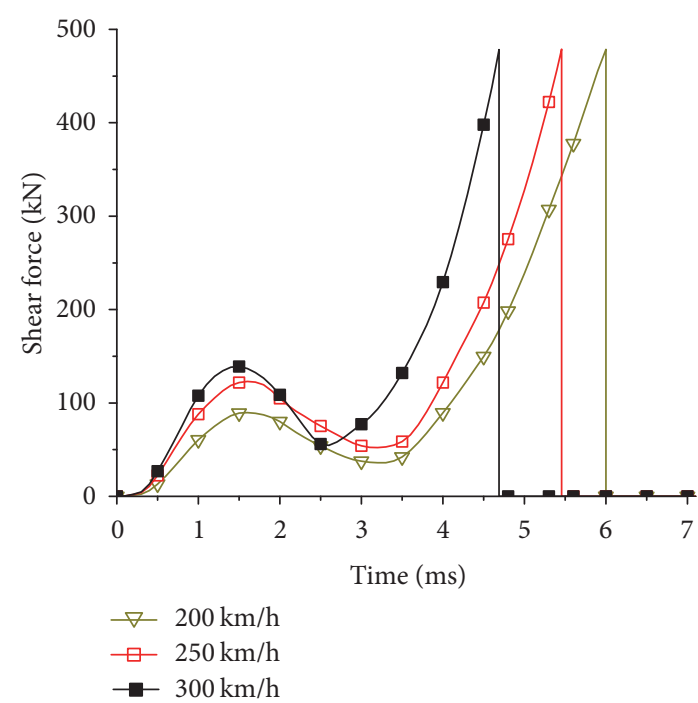

(d) Bolt $\mathrm{E}$

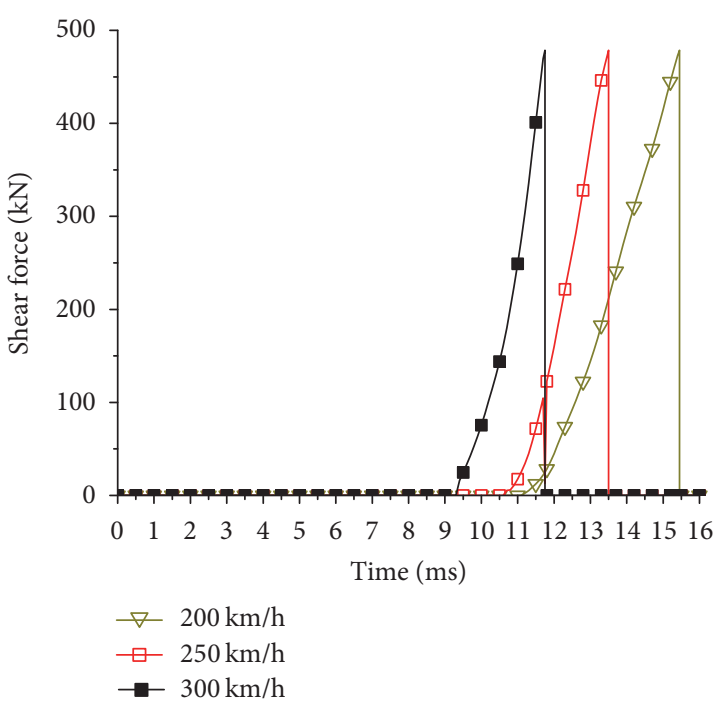

(f) Bolt G

FIGURE 22: The Shear force time history curves for bolts A, B, C, E, F, and G. 
discussed based on the numerical results. In total, 108 bolts were considered in the proposed FE model (Model I), while eight bolts exhibited failure under the HST impact load. A parametric study was conducted based on the proposed FE model without taking into account the bolt failure behavior (Model II). According to the numerical results, the influence of bolt failure on the dynamic behavior of the shield tunnel in terms of the damage behavior and the damage displacement condition of the tunnel segment was examined. Besides, in order to reveal the influence of train impact speed on force conditions and failure characteristics of bolt, three impact loading conditions obtained from three different train running speeds $(200 \mathrm{~km} / \mathrm{h}, 250 \mathrm{~km} / \mathrm{h}$, and $300 \mathrm{~km} / \mathrm{h})$ were applied on the intrados of segment lining. The conclusions are listed as follows:

(1) Under the HST impact, the bolt failure was firstly observed around the target segment (F2) and then happened around its adjacent segment (F3). It was found that the bolt failure generally occurred in sequence along the travel direction of the train.

(2) Generally, there were two failure types of the joint bolts, the tensile failure and the shear failure. According to the travel direction of the train, the bolts connected with the target segment in the backward direction along the longitudinal direction usually exhibit failure due to tension. The bolts connected to the target segment in the forward direction along the longitudinal direction and the circumferential bolts connected to the target segment usually exhibit failure due to shear.

(3) Without considering the bolt failure, the maximum tensile and shear forces of the bolts were greatly larger than the respective ultimate bearing capacities, up to 3-6 times. This led to a significant difference between the numerical results and the practical values. This shows that only taking into account the bolt failure in the FE model is able to allow for a realistic prediction of the shield tunnel under the HST impact load.

(4) During the analysis, the compressive damage was mainly observed on the target segment and its adjacent segments. The influence of compressive damage was relatively small on other segments. The compressive damage distribution area in longitudinal direction was greatly larger than that in the circumferential direction. Besides, the maximum compressive damage variables in both models (with and without considering the bolt failure) were almost identical. However, the damage area in the model without considering the bolt failure was almost $30.0 \%$ larger than the area in the model considering the bolt failure.

(5) Generally, with respect to the travel direction of the train, the displacement of the target segment and the segment in front of it in the model considering the bolt failure was larger than the displacement in the model without considering the bolt failure. However, the displacement of the segment behind the target segment behaved in the opposite way. This was possibly due to the fact that the displacement constraints on the segments were released, and the force transmissions from the bolts to the segments were removed after the bolt failure happened under the HST impact.

(6) After applying three different impact loads on the target segment F2 (which represents three different train speeds, $200 \mathrm{~km} / \mathrm{h}, 250 \mathrm{~km} / \mathrm{h}$, and $300 \mathrm{~km} / \mathrm{h}$ ), the bolts were generally divided into two groups according to the failure time interval. The failure time interval of the second group (bolt $\mathrm{G}$ ) was 9.0 ms later than the failure time interval of the first group (bolts A-F). The influences of the train speed on the failure types, failure sequence, and trend of tensile and shear forces time history curves of the bolts are very little. However, the bolt failure time is reduced with the increase of the train speed. In other words, increasing the train speed will lead to the occurrence of the bolt failure much easier and faster.

Based on the numerical results of the proposed FE model, an optimization design method for preventing the shield tunnel from the hazard induced by the impact load from a derailed train was proposed according to the failure characteristics (e.g., failure time, types, and sequence) of the joint bolts observed in this study. Firstly, the bearing capacities of the joint bolts in the possible failure segments are suggested to be enhanced via improving the steel class or strengthening by other engineering materials. Secondly, the tunnel segments are suggested to be partially strengthened by optimizing the arrangement of buffer structures in possible damage position (e.g., at the same height of the HST in the longitudinal direction of the shield tunnel). In general, it is envisaged that further work on the safety assessment and the design optimization should be carried out in the future.

\section{Competing Interests}

The authors declare that they have no competing interests.

\section{Acknowledgments}

The authors wish to acknowledge the support provided by the National Natural Science Foundation of China (no. 51278425; no. 51178400), Project of Science and Technology Research, and Development Program of China Railway Corporation (2014G004-H) to this study.

\section{References}

[1] X. Liu, M. R. Saat, and C. P. L. Barkan, "Analysis of causes of major train derailment and their effect on accident rates," Transportation Research Record, vol. 2289, pp. 154-163, 2012.

[2] C. Ulianov, F. Defossez, G. V. Franklina, and M. Robinson, "Overview of freight train derailments in the EU. Causes, impacts, prevention and mitigation measures," in Proceedings of the Transport Research Arena (TRA) 5th Conference: Transport Solutions from Research to Deployment, 2014. 
[3] A. Marissal, B. Marguet, and P. Drazetic, "Crash behaviour of guided vehicles," GEC Alstorm Technical Review, no. 9, pp. 5562, 1992.

[4] G. J. Gao and H. Q. Tian, “Train's crashworthiness design and collision analysis," International Journal of Crashworthiness, vol. 12, no. 1, pp. 21-28, 2007.

[5] C. Baykasoglu, E. Sunbuloglu, E. Bozdag, F. Aruk, T. Toprak, and A. Mugan, "Railroad passenger car collision analysis and modifications for improved crashworthiness," International Journal of Crashworthiness, vol. 16, no. 3, pp. 319-329, 2011.

[6] H. Shao, P. Xu, S. Yao, Y. Peng, R. Li, and S. Zhao, "Improved multibody dynamics for investigating energy dissipation in train collisions based on scaling laws," Shock and Vibration, vol. 2016, Article ID 3084052, 11 pages, 2016.

[7] D. Tyrell, K. Jacobsen, and E. Martinez, "A train-to-train impact test of crash energy management passenger rail equipment: structural results," American Society of Mechanical Engineers, Paper, vol. IMECE2006-13597, 2006.

[8] S. W. Kirkpatrick, M. Schroeder, and J. W. Simons, "Evaluation of passenger rail vehicle crashworthiness," International Journal of Crashworthiness, vol. 6, no. 1, pp. 95-106, 2001.

[9] W. Zhai and Z. Cai, "Dynamic interaction between a lumped mass vehicle and a discretely supported continuous rail track," Computers \& Structures, vol. 63, no. 5, pp. 987-997, 1997.

[10] S. H. Ju, "Nonlinear analysis of high-speed trains moving on bridges during earthquakes," Nonlinear Dynamics, vol. 69, no. 1-2, pp. 173-183, 2012.

[11] X. Yang, H. Wang, and X. Jin, "Numerical analysis of a trainbridge system subjected to earthquake and running safety evaluation of moving train," Shock and Vibration, vol. 2016, Article ID 9027054, 15 pages, 2016.

[12] J. W. Kwark, E. S. Choi, Y. J. Kim, B. S. Kim, and S. I. Kim, "Dynamic behavior of two-span continuous concrete bridges under moving high-speed train," Computers and Structures, vol. 82, no. 4-5, pp. 463-474, 2004.

[13] M. Tanabe, N. Matsumoto, H. Wakui, M. Sogabe, H. Okuda, and Y. Tanabe, "A simple and efficient numerical method for dynamic interaction analysis of a high-speed train and railway structure during an earthquake," Journal of Computational and Nonlinear Dynamics, vol. 3, no. 4, Article ID 041002, 2008.

[14] J.-D. Yau, Y.-B. Yang, and S.-R. Kuo, "Impact response of high speed rail bridges and riding comfort of rail cars," Engineering Structures, vol. 21, no. 9, pp. 836-844, 1999.

[15] Q. X. Yan, B. Li, P. Geng, C. Chen, C. He, and W. B. Yang, "Dynamic response of a double-lined shield tunnel to train impact loads," Tunnelling and Underground Space Technology, vol. 53, pp. 33-45, 2016.

[16] A. M. M. Wood, "The circular tunnel in elastic ground," Geotechnique, vol. 25, no. 1, pp. 115-127, 1975.

[17] K. M. Lee, X. Y. Hou, X. W. Ge, and Y. Tang, "An analytical solution for a jointed shield driven tunnel lining," International Journal for Numerical and Analytical Methods in Geomechanics, vol. 25, no. 4, pp. 365-390, 2001.

[18] Y. Koyama, "Present status and technology of shield tunneling method in Japan," Tunnelling and Underground Space Technology, vol. 18, no. 2-3, pp. 145-159, 2003.

[19] H. Murakami and A. Koizumi, "Study of load-bearing capacity and mechanics of shield segment ring," Proceedings of the Japan Society of Civil Engineers, vol. 272, no. 4, pp. 103-115, 1978.

[20] A. Koizumi, "On the design method of the shield tunnel lining," Science \& Engineering, no. 56, pp. 125-177, 1992.
[21] W. Q. Ding, Q. Z. Yue, G. L. Tham, H. H. Zhu, C. F. Lee, and T. Hashimoto, "Analysis of shield tunnel," International Journal for Numerical and Analytical Methods in Geomechancis, vol. 28, no. 1, pp. 57-91, 2004.

[22] H. Zhu and L. Tao, "Study on two beam-spring models for the numerical analysis of segments in shield tunnel," Yantu Lixue/Rock and Soil Mechanics, vol. 19, no. 2, pp. 26-32, 1998.

[23] X.-Y. Zhuang, X.-J. Zhang, and H.-H. Zhu, "3-D finite element model for destruction process of segment joints of shield tunnel using elastoplastic and damage constitutive methods," Yantu Gongcheng Xuebao/Chinese Journal of Geotechnical Engineering, vol. 37, no. 10, pp. 1826-1834, 2015.

[24] L.-Z. Wang, Z. Wang, L.-L. Li, and J.-C. Wang, "Construction behavior simulation of a hydraulic tunnel during standpipe lifting," Tunnelling and Underground Space Technology, vol. 26, no. 6, pp. 674-685, 2011.

[25] J. S. Chen and H. H. Mo, “Three-dimensional finite element analysis of mechanical behaviors of shield tunnel segment during construction," Chinese Journal of Rock Mechanics and Engineering, vol. 25, supplement 2, pp. 3482-3489, 2006.

[26] ABAQUS, Theory Manual Version 6.10, Hibbitt, Karlsson \& Sorensen Inc., Rhode Island, RI, USA, 2010.

[27] Ministry of Construction of the People's Republic of China, "Code for design of concrete structures," GB 50010-2010, China Architecture and Building Press, Beijing, China, 2010 (Chinese).

[28] Y. H. Takano, "Guidelines for the design of shield tunnel lining (ITA WG 2 report)," Tunnelling and Underground Space Technology, vol. 15, no. 3, pp. 303-331, 2000.

[29] CECS, “Code for design of steel structures (in Chinese)," GB 50017-2003, China Architecture and Building Press, Beijing, China, 2003.

[30] D. Negrut, R. Rampalli, G. Ottarsson, and A. Sajdak, "On an implementation of the Hilber-Hughes-Taylor method in the context of index 3 differential-algebraic equations of multibody dynamics (DETC2005-85096)," Journal of Computational and Nonlinear Dynamics, vol. 2, no. 1, pp. 73-85, 2007.

[31] B. Nedjar, "Elastoplastic-damage modelling including the gradient of damage: formulation and computational aspects," International Journal of Solids and Structures, vol. 38, no. 30-31, pp. 5421-5451, 2001. 


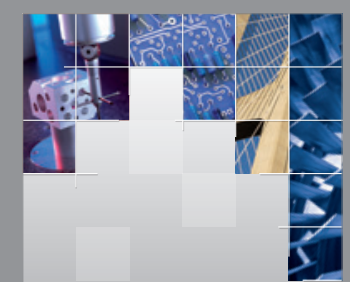

\section{Enfincering}
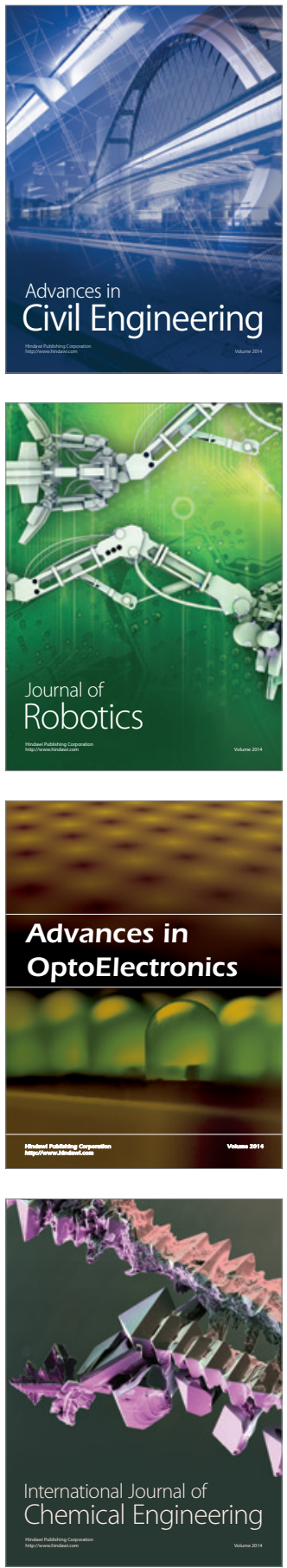

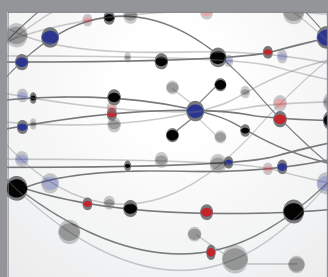

The Scientific World Journal

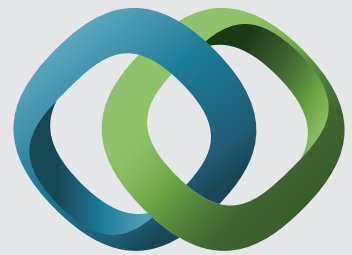

\section{Hindawi}

Submit your manuscripts at

https://www.hindawi.com
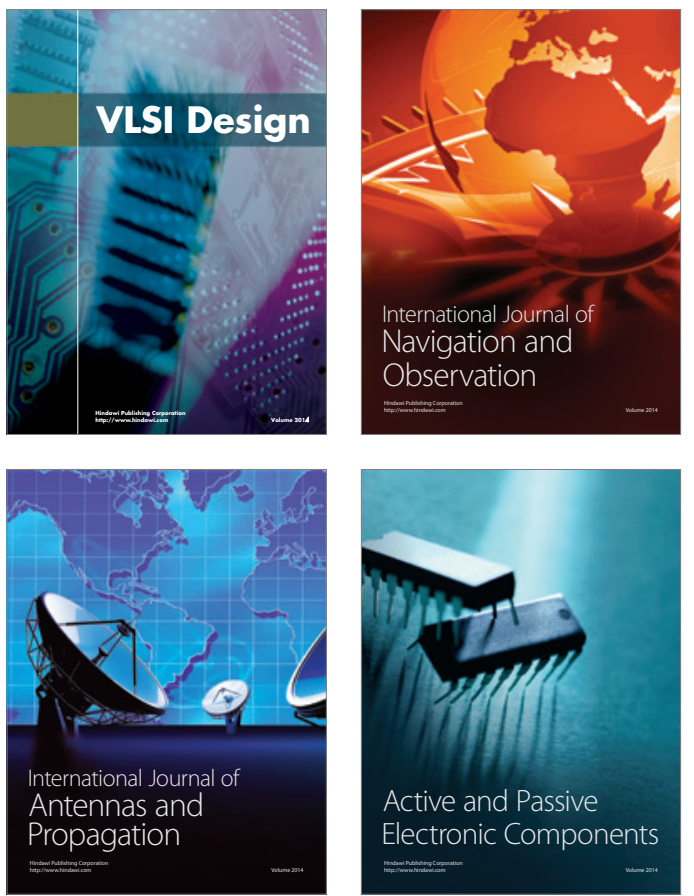
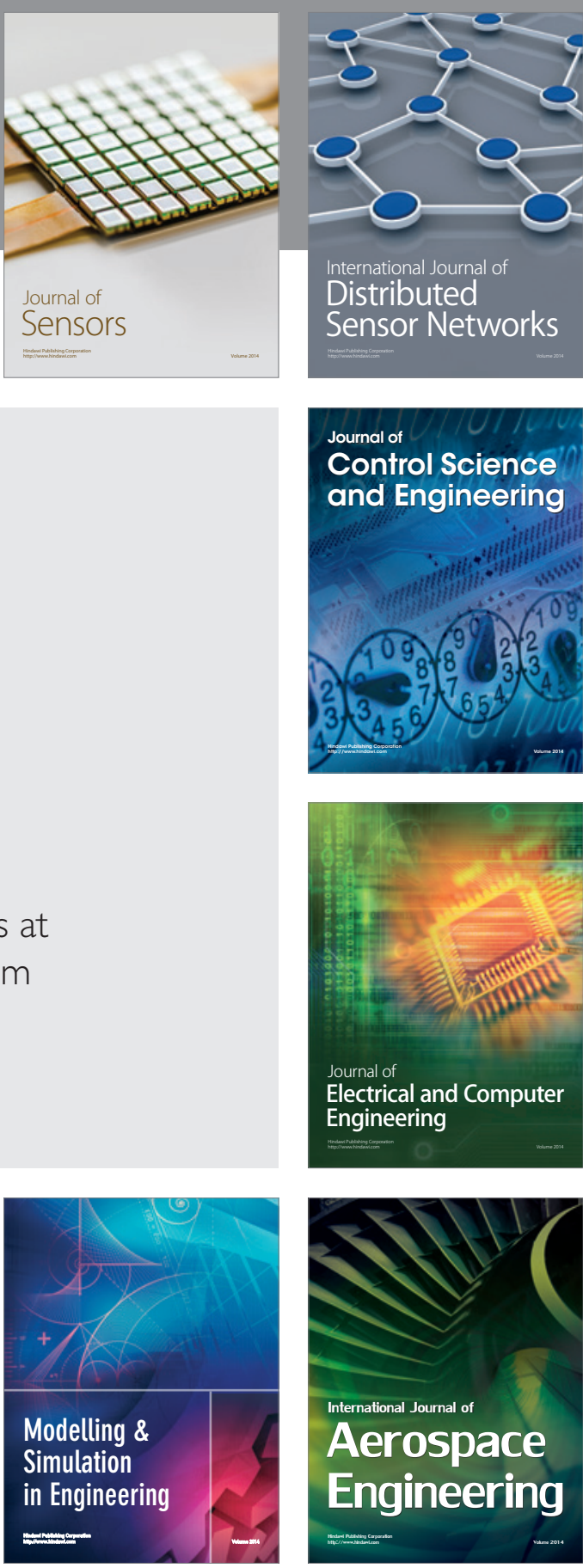

International Journal of

Distributed

Sensor Networks

$-$

Joumal of

Control Science

and Engineering
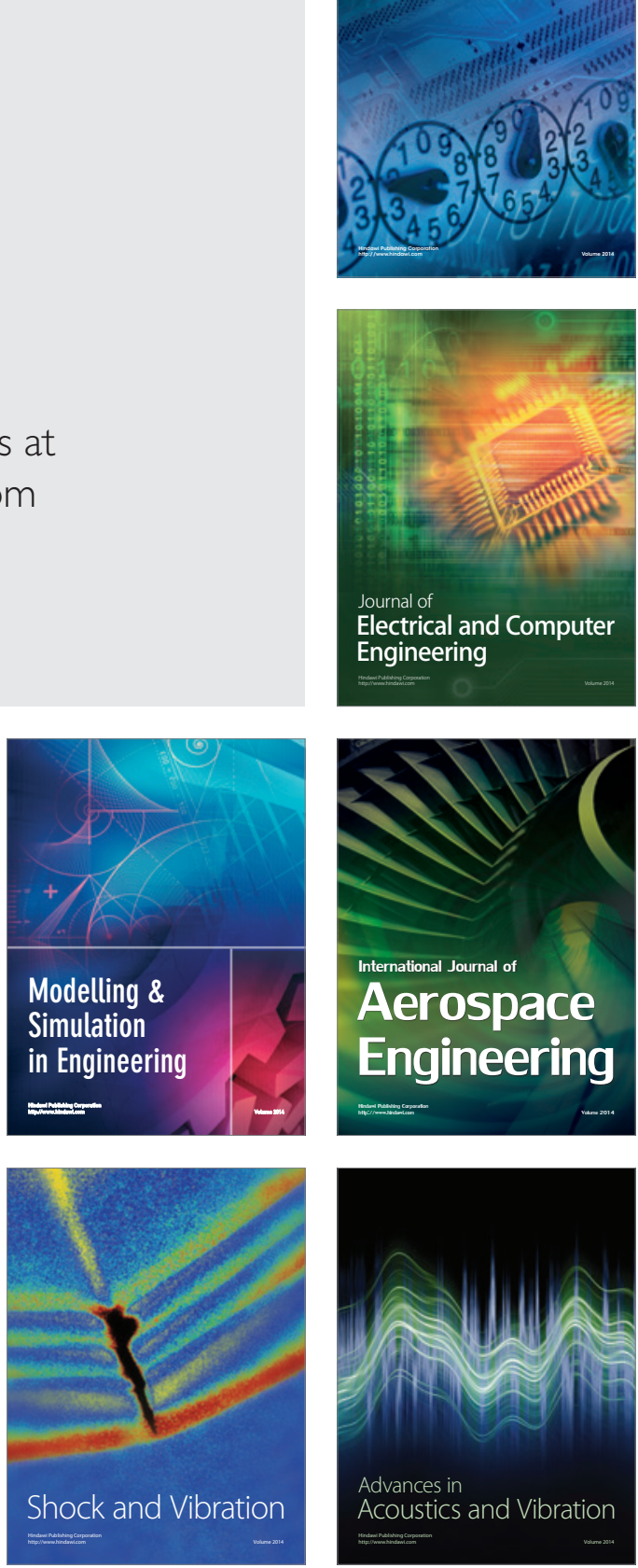